\title{
Role of Multiomics Data to Understand Host-Pathogen Interactions in COVID-19 Pathogenesis
}

Shalini Aggarwal, ${ }^{\S}$ Arup Acharjee, ${ }^{\S}$ Amrita Mukherjee, Mark S. Baker, and Sanjeeva Srivastava*

Cite This: https://dx.doi.org/10.1021/acs.jproteome.0c00771

Read Online

ACCESS | Lلll Metrics \& More | 四 Article Recommendations | S1 Supporting Information

ABSTRACT: Human infectious diseases are contributed equally by the host immune system's efficiency and any pathogens' infectivity. Severe acute respiratory syndrome coronavirus 2 (SARS-CoV-2) is the coronavirus strain causing the respiratory pandemic coronavirus disease 2019 (COVID-19). To understand the pathobiology of SARS-CoV-2, one needs to unravel the intricacies of host immune response to the virus, the viral pathogen's mode of transmission, and alterations in specific biological pathways in the host allowing viral survival. This review critically analyzes recent research using high-throughput "omics" technologies (including proteomics and metabolomics) on various biospecimens that allow an increased understanding of the pathobiology of SARS-CoV-2 in humans. The altered biomolecule profile facilitates an understanding of altered biological pathways. Further, we have performed a meta-analysis of significantly altered biomolecular profiles in

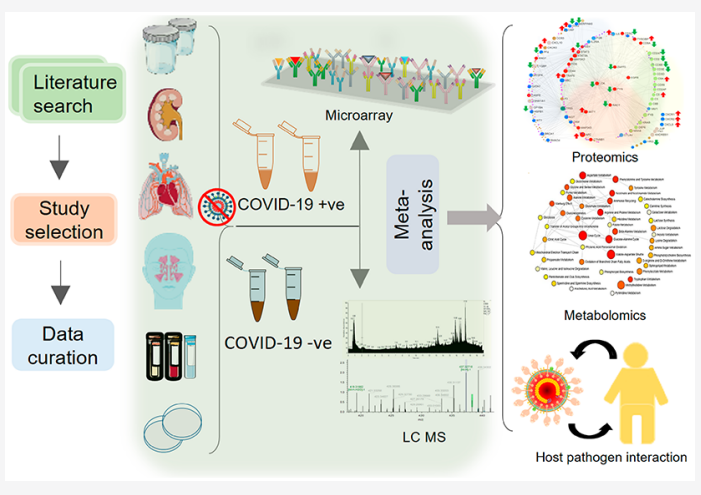
COVID-19 patients using bioinformatics tools. Our analysis deciphered alterations in the immune response, fatty acid, and amino acid metabolism and other pathways that cumulatively result in COVID-19 disease, including symptoms such as hyperglycemic and hypoxic sequelae.

KEYWORDS: SARS-CoV-2, COVID-19, proteome microarray, mass spectrometry, proteomics, metabolomics, immune response, pathways, altered biomolecules

\section{INTRODUCTION}

Coronavirus disease 2019 (COVID-19) is caused by a positivesense RNA virus named severe acute respiratory syndrome coronavirus 2 (SARS-CoV- 2$)^{1}$ belonging to the $\beta$-genus of the coronavirus family. ${ }^{2}$ The SARS-CoV-2 virus "spike" protein attaches to host angiotensin-converting enzyme 2 (ACE2) proteins located on the surface of subsets of human cells in a process that is aided by endogenous host proteases such as furin and the transmembrane serine protease 2 (TMPRSS2). ${ }^{3-6}$ Clinically, COVID-19 manifests itself through many symptoms. Infection of the human respiratory tract and lungs leads to cough, myalgia, and fever and in some patients to acute respiratory distress syndrome. ${ }^{7}$ While most patients experience very mild-to-moderate symptoms, around one in five patients develop pneumonia coupled with severe respiratory distress. These patients require treatment in hospital intensive care units (ICU), where infection can lead to multiorgan dysfunction, failure, and sometimes death. ${ }^{8-10}$ The virus is extremely infectious and has triggered a devastating global pandemic. The COVID-19 pandemic has led to urgent and intense investigations of this disease, its causative agent, and its interaction with the human host. However, the diverse pathophysiological pathways perturbed under diverse conditions of comorbidity and degrees of severity during the disease course and disease sequelae remain unclear and are subject to ongoing multiomic investigations.

The 30-kb SARS-CoV-2 viral (Figure 1) genome codes for two polyproteins, the open reading frame la (Orfla) and the open reading frame $1 \mathrm{ab}$ (Orflab), ${ }^{11}$ whose autoproteolytic processing produces a replicase-transcriptase complex of 16 nonstructural proteins, NSP1-NSP16. ${ }^{12-14}$ The $3^{\prime}$ end of the viral genome encodes four structural proteins (termed envelope $(\mathrm{E})$, membrane $(\mathrm{M})$, nucleocapsid $(\mathrm{N})$, and spike $(\mathrm{S})$ proteins, as well as five accessory proteins (called Orf3a, Orf6, Orf7a, Orf8, and Orf10)). The NSP1-NSP16 are involved in viral RNA replication and transcription. The $E$ and $M$ proteins are essential in viral assembly, and the $\mathrm{N}$ protein is necessary for viral RNA synthesis. The $S$ protein is found on the surface of the viral particle and enables host infection by binding to the host cell surface receptor angiotensin-converting enzyme 2 (ACE2) via the S-protein's receptor-binding domain (RBD) within subunit 1 of the S-protein. ${ }^{12,15}$ Proteolytic cleavage through the human

Received: September 30, 2020 


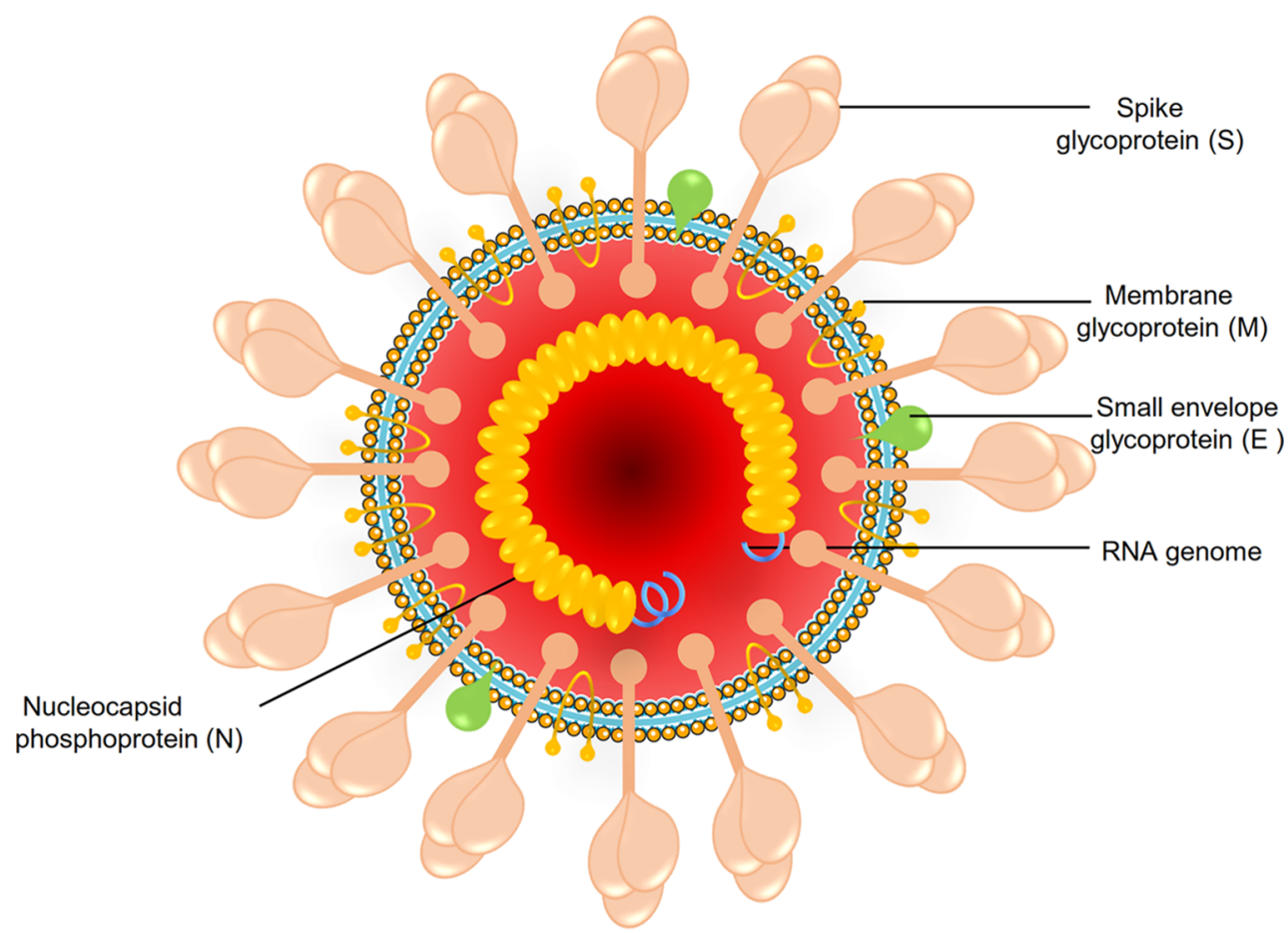

Figure 1. Structure of SARS-CoV-2. The vital RNA genome that is encoded is packaged within the protective nucleocapsid phosphoprotein (N) inside the core particle. This is surrounded by an outer membrane envelope made of lipid bilayer interspersed with viral proteins viz. spike glycoprotein (S), membrane glycoprotein (M), and small envelope glycoprotein (E). This figure was created using Servier Medical Art templates, which are licensed under a Creative Commons Attribution 3.0 Unported License; https://smart.servier.com.

proteases furin and transmembrane serine protease 2 $(\text { TMPRSS2) })^{3-6}$ facilitate this protein-protein interaction, leading to successful infection of host cells.

High-throughput technologies have allowed the unraveling of mechanistic pathways of viral infection at an astoundingly rapid pace. ${ }^{16}$ On one hand, in-depth proteome analysis using mass spectrometry (MS)-based proteomics has come of age and has previously allowed disease pathways of the Ebola virus, ${ }^{17}$ Zika virus, ${ }^{18}$ Chikungunya virus, ${ }^{19}$ and dengue ${ }^{20}$ and influenza virus infection to be unraveled. ${ }^{21}$ Also, technologies such as proteome arrays $^{22}$ have been used to assess host responses in other viral diseases such as papillomavirus, ${ }^{23}$ rubella virus, ${ }^{24}$ herpes simplex virus 1 and $2,{ }^{25}$ and Zika virus. ${ }^{26}$ Equally, MS-based metabolomics has been used by various researchers in search of potential diagnostics biomarker candidates in various diseases, namely autism spectrum disorders in children, ${ }^{27}$ oncometabolite in cancer, ${ }^{28,29}$ infectious diseases such as tuberculosis, $^{30}$ and Lyme disease. ${ }^{31}$ Moreover, viruses as infectious agents are reported to alter host metabolism for its survival and reproduction. ${ }^{32,33}$ SARS-CoV-2 being a virus is suspected of doing the same, and hence, metabolomics profiling of infected hosts is one possible way to diagnose affected patients.

Since the start of the COVID-19 pandemic, many groups have reported the use of MS and protein microarrays to provide critical "omics" information that has helped formulate strategies to combat the virus. In this article, we review COVID-19 proteomics and metabolomics studies to provide the reader with an understanding of the pathogenesis of the disease and host response to infection. Additionally, we provide a critical view of pitfalls in these studies and explore potential new avenues for proteomics and metabolomics research to advance studies into COVID-19 biology and host responses.

\section{PHYSIOLOGICAL RESPONSES IN COVID-19 PATIENTS (BLOOD TEST REPORTS, SERUM PROTEOMICS, AND AUTOPSY STUDIES)}

Viruses are known for using host machinery for their replication and survival, resulting in perturbations to the host system. This leads to biochemical warfare between the two, wherein the levels of metabolites, transcripts, and proteins are altered. Host physiology ultimately changes due to the disease and is involved in the generation of symptoms. Many studies have investigated biochemical and physiological perturbations in human host cells infected with SARS-CoV-2. Analysis of COVID-19 disease groups with varying severity has shown altered blood profiles, including lower lymphocyte counts (lymphopenia), increased erythrocyte sedimentation rate, decreased procalcitonin, and upregulation of biomarkers such as lactate dehydrogenase, interleukin-6 (IL-6), C-reactive protein (CRP), D-dimer, and serum ferritin, among others. ${ }^{8,10,33,34}$ However, exact biomarkers prognostically predicting COVID-19 severity remain elusive to date.

\section{OMICS-BASED TECHNOLOGY PLATFORM FOR COVID-19 RESEARCH}

\subsection{Protein Microarrays}

MS-based discovery approaches to COVID-19 biological samples have provided novel and objective data about the biology of infection. However, some common handicaps of MSbased serum/plasma approaches are the need for the depletion of high abundance proteins and ion suppression, which can be circumvented by the use of protein microarrays. Protein microarrays provide a high-throughput platform for targeted and untargeted proteomics by using either antibodies against hundreds of proteins or peptides in a microarray panel. In the 


\section{Microarray based assays}

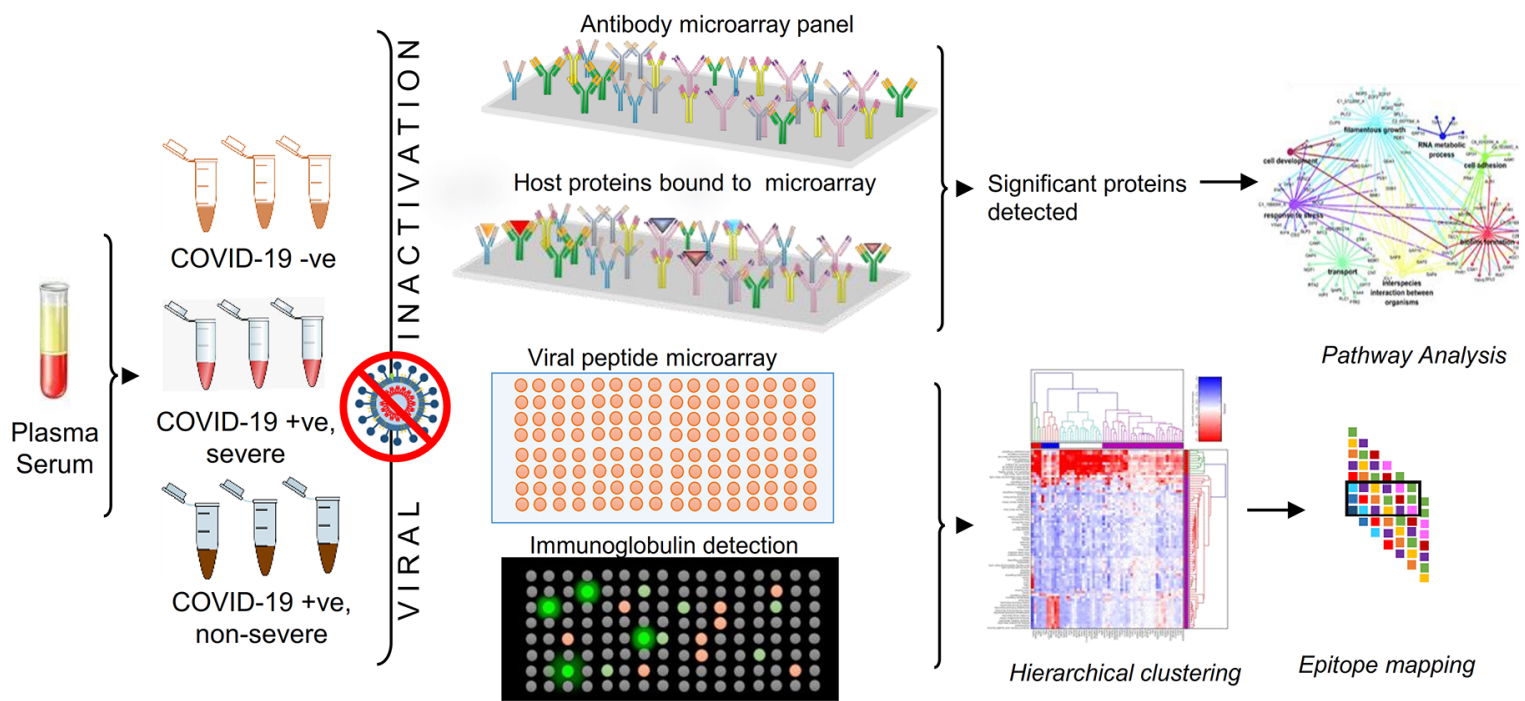

II. Mass Spectrometry based assays

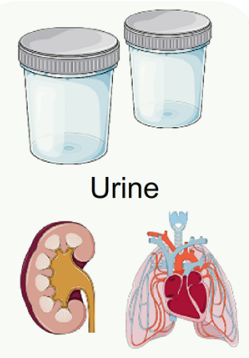

Organs (Autopsy)

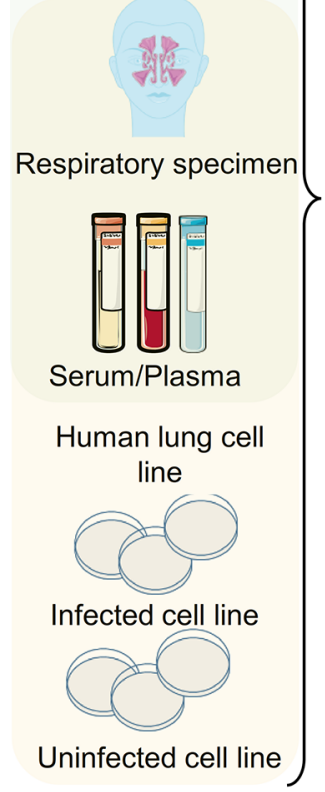

\section{A. Proteome profile}

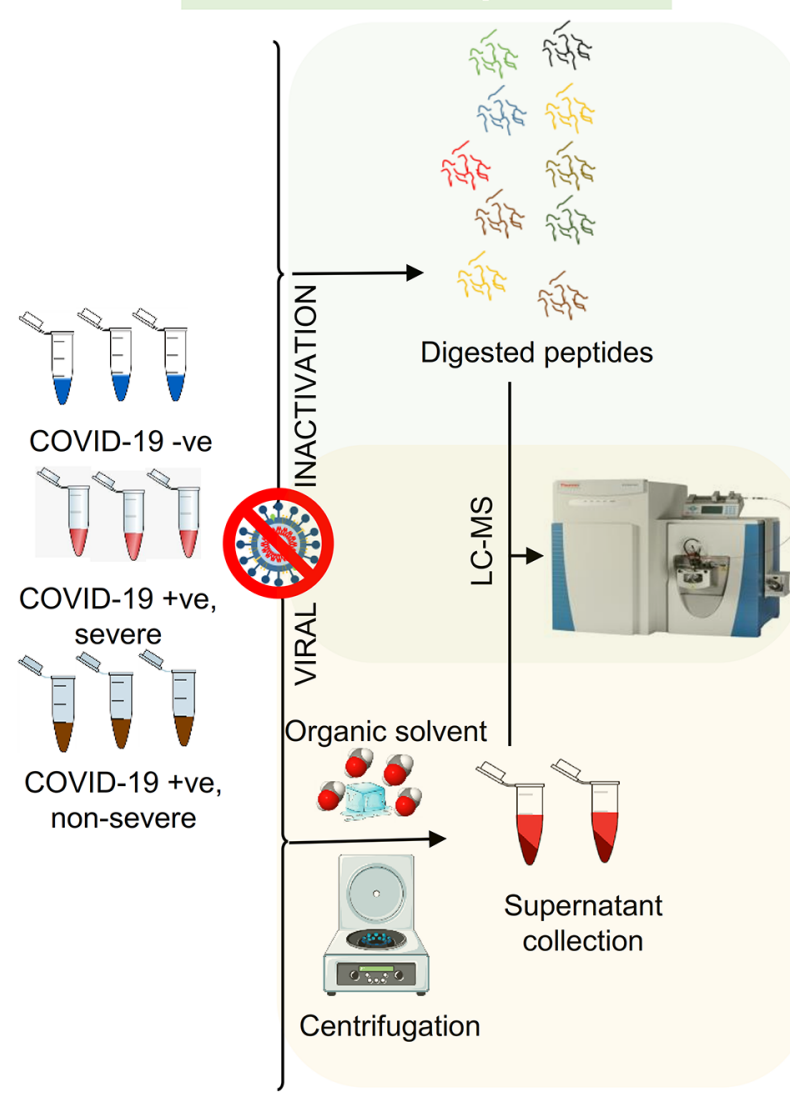

B. Metabolome profile

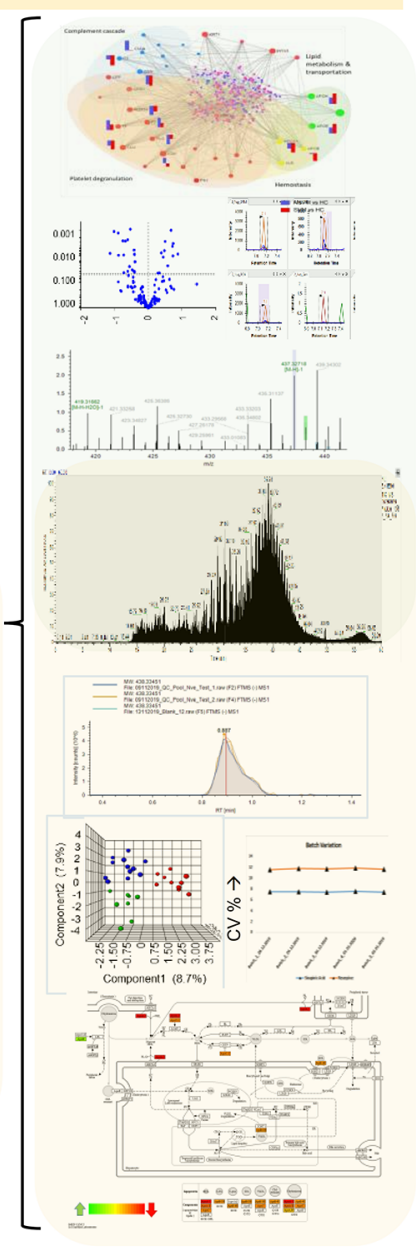

Figure 2. Depicting the workflow of (I) microarray based technologies and (II) mass spectrometry based technologies: (A) untargeted and targeted proteome profiling; (B) untargeted and targeted metabolome profiling of human biospecimens and cell line model to understand altered metabolites. This figure was created using Servier Medical Art templates, which are licensed under a Creative Commons Attribution 3.0 Unported License; https:/ / smart.servier.com.

case of pathogen-borne diseases, these can also be used for proteome-wide investigations to study the humoral immune response to discover antibodies of multiple isotypes against multiple antigens. ${ }^{35}$ Further, by using arrays printed with overlapping peptides from the SARS-CoV-2 proteome or antibodies, some researchers have probed COVID-19 to 
investigate interesting biological questions concerning fundamental protein-protein interactions (Figure 2A).

\subsection{MS-Based Metabolomics and Proteomics}

Metabolites are small molecules $(<1000 \mathrm{Da})$ that play a crucial role in managing pathways in any organism. ${ }^{36}$ They include nucleotides, nucleosides, amino acids, glucose moieties, and more. Metabolites work at all the levels of central dogma to manage interrelated pathways meticulously. ${ }^{37,38}$ Metabolites can be extracted from urine, saliva, or blood samples, which makes them easily accessible and desired biospecimens for biomarker search. Metabolome profiling of infected hosts is a possible way to diagnose a patient. Metabolite processing being quickest and easiest as compared to any other biomolecule processing makes it highly favored for rapid diagnostics. MSbased metabolomics of COVID-19 positive infected patients has revealed various affected pathways such as amino acid, fatty acid, and interleukin metabolism pathways. One metabolomics study involved viral inactivation using ethanol for various time intervals depending on the concentration of ethanol used; preferably $70 \%$ ethanol for $5 \mathrm{~min}$ of vigorous shaking is reported to be sufficient. ${ }^{39}$ Inactivated samples of COVID-19 infected patients can be extracted using various concentrations of organic solvents such as acetonitrile or methanol. ${ }^{40,39}$ The extracted metabolites can be used for the identification and annotation of metabolites based on the Metabolomics Standard Initiative (MSI) levels. ${ }^{41}$

Proteins are the essential workhorses that drive life. As opposed to the genome, the proteome is far more dynamic, and alterations in physiological processes reflect in differentially expressed proteomic signatures. In the past two decades, proteomics has been successfully used to investigate coronavirus diseases such as SARS and MERS-CoV, ${ }^{42}$ as well as several other infectious RNA viruses such as HIV, ${ }^{43}$ influenza, ${ }^{21}$ and Dengue fever. ${ }^{20}$ Several MS-based proteomics studies have been performed on a diverse range of clinical sample types since the COVID-19 pandemic began, including plasma, sera, nasopharyngeal swabs, gargle solutions, urine, and postmortem tissues. These studies have cumulatively provided mechanistic insights into COVID-19 and revealed how alterations in protein expression profiles can be used as a classifier of COVID-positive and COVID-negative cases and may also assist in characterizing mild from severe cases (Figure 2B).

\subsection{Other Techniques}

3.3.1. Raman Spectroscopy: The property of inelastic bending of visible light called the Raman effect ${ }^{44}$ has been utilized to detect viruses noninvasively. By observing the change in Raman spectra, this method can detect viral infection in vitro only three hours after the addition of the virus to the culture medium. ${ }^{45}$ Recently, Desai et al. used this method to screen for RNA viruses in saliva, employing a group of 65 Raman spectral features that typically point to the RNA moieties. They achieved a prediction accuracy of $91.6 \% .{ }^{46}$ However, despite its promise, little has been studied on the use of Raman spectroscopy to develop clinical tests for COVID-19 diagnostics.

3.3.2. NanoString: SARS-CoV-2 pathobiology understanding is also facilitated by direct RNA expression analysis using nCounter technology developed by NanoString, without introducing PCR biases and low sample quantity. ${ }^{47}$ This study has shown increased expression of chemokine genes and altered expression of other genes, which are reported to be in association with acute tubular injury when compared to controls. $^{47}$ Cytokine levels elevated in severe COVID-19 compared to nonsevere include granulocyte cell-stimulating factor (GM-CSF), interleukins (IL; 2, 6, 7, and 10), interferon $\gamma$ induced protein $10 \mathrm{kDa}$ (IP-10), monocyte chemoattractant protein 1 (MCP1), macrophage inflammatory proteins 1A (MIP1A), tumor necrosis factor-alpha (TNF- $\alpha$ ), ${ }^{48}$ and TNFlambda (TNF- $\lambda) .{ }^{47}$ Also, the elevation of ACE2 expression in proximal tubule cells of targeted patients was observed. These researchers also observed a slight elevation of podocytes along with parietal epithelial cell expression. ${ }^{48,49}$ The $\mathrm{Wu}$ et al. group also reported that COVID-19 positive patients with collapsing glomerulopathy and acute kidney injury (AKI) possessed a highrisk genotype of apolipoprotein L1 (APOL1). ${ }^{48}$ The study suggests the crucial role of SARS-CoV-2 in leading a susceptible individual toward collapsing glomerulopathy if an individual has AKI and proteinuria condition, making them particularly susceptible.

3.3.3. Next-Generation Sequencing: Next-generation sequencing or NGS is a pillar of high-throughput omics that has aided our understanding of the dynamics of the viral genome and how it interacts and coevolves with the host. First, NGS technology enabled rapid identification of the causative agent of COVID $-19^{1}$ and helped us understand its origins by sequencing of the initial Wuhan seafood market pneumonia virus strain. ${ }^{50}$ Secondarily, NGS technology has assisted us to deduce viral proteomes as well as laying the foundation for further omics studies. Furthermore, the availability of the SARS-CoV-2 sequence expedited the rapid development of nucleic acidbased diagnostics ${ }^{51}$ and set the ball rolling for research on vaccines and therapeutics. Moreover, NGS technologies have helped us in our understanding of the evolution of viral genomes, ${ }^{52}$ which has proven critical for tracing viral epidemiology. ${ }^{53}$ NGS-based approaches have allowed for the detection of more than 2-3 viral genomes or transcriptome fragments that can be detected easily using methods such as SARSeq (saliva analysis by RNA sequencing), which can detect the presence of SARS-CoV-2 and other respiratory viruses such as influenza $\mathrm{A}$ and $\mathrm{B} .{ }^{54}$ Moreover, the metagenomic NGS (mNGS) protocol that allows detection of SARS-CoV-2 and other associated pathogens present in a clinical sample at once has aided the discovery of coinfections that would have been otherwise missed. ${ }^{55}$ In a similar study, a higher abundance of Propionibacteriaceae and reductions in Corynebacterium accolens was observed in COVID-19 negative patients compared to COVID-19 positive patients. ${ }^{56}$ Next-gen immunosequencing performed from blood collected from COVID-19 positive patients as well as recovered patients has been used to generate a library of more than 14 billion $\mathrm{B}$ and $\mathrm{T}$-cell receptor sequences to decode host humoral responses generated postinfection. ${ }^{57}$ The same study showed that converging IGHV3-driven BCR clusters is mostly responsible for producing SARS-CoV-2 antibodies, whereas interferon (especially IFN-I \& III) responses and early CD4+ and CD8+ $\mathrm{T}$ cell activation were key factors driving the clonality of $\mathrm{T}$ cell receptors.

\section{APPLICATION OF "OMICS" TECHNOLOGIES IN DISEASE DIAGNOSIS AND PROGNOSIS}

\subsection{Proteome Biomarkers}

4.1.1. Plasma/Sera Proteomics: Almost all studies, including those measuring plasma and sera proteomic changes in COVID-19 positive patients, have expected outcomes when it comes to assessing postinfection host responses. Starting from the first line defenders of innate immunity to neuronal injury, 
biomolecular evidence of various physiological changes has been observed across the spectrum. In one study, a comprehensive blood-proteome analysis of severe and critical COVID-19 patients was performed using inflammation, autoimmune, cardiovascular, and neurology panels. The study found that 269 proteins were differentially expressed (120 up-regulated and 149 down-regulated), including neurofibromin 2 (NF2), which was suggested by the authors to be a down-regulated specific plasma biomarker for COVID-19. ${ }^{58}$ NF2 is a well-known tumor suppressor protein ${ }^{39}$ and, according to the authors, may activate antimitogenic signaling or uncontrolled cell division, where the mechanism of NF2 activation postinfection remains completely unknown. The same study revealed 19 biomarkers for infection duration (tested as mild vs critical groups), of which 13 specifically expressed proteins identified the mild patient cohort (BOC, KYNU, SPRY2, KIM1, SCF, MANF, SLAMF1, CD84, SCF, PADI2, PAPPA, CLEC4A, TANK) and six proteins (DECR1, TPSAB1, TF, GDF-8, GZMA, BCAN) identified the critical COVID-19 patient cohort. Interestingly, the study also reported biomarkers of neuronal injury in severe and critical COVID-19 patients. The study concluded that a storm of glial response and astrocytic activation was a common trait in patients with severe infection. The same group reported platelet degranulation to be down-regulated in SARS-CoV-2-infected patients, and this was confirmed in severe COVID-19 patients by examining their low platelet levels. Platelet degranulation associates with glycerophospholipids, which has also been reported to be sequentially decreased in SARS-CoV-2 patients.

Another study of COVID-19 serum proteome on 49 subjects observed dramatic up-regulation of the IL- 6 target proteins (JNK, STAT3, and p53). The authors proposed IL-6 signaling to be the most up-regulated upstream pathway in the disease. ${ }^{59}$ Components of the coagulation cascade were also dramatically changed (increased factors are Factor- 2, 5, 7, and 10; decreased factors are XIIIb and gelsolin) coupled with increased levels of some serine-protease inhibitors or SERPINs (SERPINA1, SERPINA3, and SERPINF2) and a few carboxypeptidases (specifically CPB2/TAFI) fibrinolytic pathways, suggesting an increased innate immune response. Patients with the highest IL6 response were also shown to show up-regulated expression of creatine kinase $\mathrm{M}$ or CKM, a hallmark of cardiac tissue damage. Interestingly, the study found the presence of antimicrobial enzymes in COVID-19-positive patients with elevated IL6 levels as compared to COVID-19 negative patients. The authors confirmed the activation of innate immune responses and reported this to be consistent with the worsening of the disease. It is possible that the selected patient cohort might have secondary bacterial/microbial infections or may be exhibiting a robust immune system response to viral proteins.

Serum protein profiling of 28 patients using an in-house antibody microarray has found many proteins up-regulated in COVID-19-positive patients. These belong to a diverse range of host cellular pathways, including those responsible for combating viral infection (e.g., MAPK, ERK1/ERK2, JAK-STAT, PI3K), inflammation, immune cell activation, and migration and also those involved in complement activation and coagulation cascades. $^{60}$ In the same study, outcomes somewhat contradictory to observations highlighted in other studies were observed, namely significant down-regulation of three pathways: neutrophil degranulation, complement activation pathway, and coagulation cascade. When the plasma of 17 COVID-19 patients, including mild and severe cases, were compared, 319 protein-groups and 27 biomarkers were found to be potent distinguishers between mild and severe COVID-19 cases. The summarized set of proteins belong to the group of diverse cellular pathways including complement factors, coagulation cascade, inflammatory and proinflammatory signaling. ${ }^{61}$

Recently, a virus-host interactome and proteomic study ${ }^{62}$ was performed using peripheral blood mononuclear cells and PBMCs extracted from COVID-19 patients. The study suggested 251 host proteins could be potentially targeted by the virus and that interactions may lead to neutrophil chemotaxis, neutrophil activation, type I interferon signaling pathway, inflammatory responses, and antigen processing and presentation.

4.1.2. Nasopharyngeal Swab/Gargle Proteomics. Nasopharyngeal swabs (NPS) are currently used for COVID-19 RT-PCR testing. This sample collection technique is noninvasive and requires less physical contact during specimen acquisition. Since NPS are collected in viral transport medium (VTM) having interfering components for proteomics, only a few MS-based proteomics studies have been performed on these specimens to date. One clinical comparison of NPS samples from 15 COVID-19 positive patients compared to 15 healthy controls revealed 17 statistically significant differentially expressed proteins between these cohorts. In agreement with other studies, these belonged to pathways involved in neutrophil degranulation, antimicrobial activity, and other elements of the innate immune system. ${ }^{63}$

Neutrophils are the first line barrier for airway infections by creating neutrophil extracellular traps (NETs) to mediate a particular type of programmed cell death. Overall, they specifically trigger immune cells to release cytokines, ${ }^{64}$ many different antimicrobial peptides, and trigger the formation of reactive oxygen species that collectively act as early antiviral defenses. $^{64}$ The same study identified highly expressed azurophil granule proteins myeloperoxidase (MPO), elastase (ELANE), cathepsin G (CTSG), azurocidin 1 (AZU1), and proteinase 3 (PRTN3) that are collectively thought to play critical roles in viral clearance, ${ }^{63}$ although it is completely unknown how neutrophils and their activation followed by degranulation play a role in modulating the immune response in the case of SARS CoV-2 infection. A different study from oro- and NPS samples detected three proteins to be present exclusively in COVID-19 patients, namely tapasin, MHC II DR $\beta$ chain, and guanylatebinding protein 1 (GBP1). ${ }^{65}$ Both tapasin and MHC II DR $\beta$ are the major components of the innate immune system, and GBP1 inhibits endothelial cell proliferation during chronic inflammation. ${ }^{66}$ This result supports the idea that SARS CoV2 triggers the innate immune system in a multitude of ways.

Another study investigated diluted gargle specimens from COVID-19 patients and developed an MS-based simple protocol that specifically detected the $\mathrm{N}$-protein, known to be the most highly expressed viral gene product. ${ }^{67}$ Although the study could detect SARS CoV-2 proteins in extremely diluted solutions, the protocol itself suffered from a lengthy analysis time and a small cohort size, which needs to be expanded in the future for translating it to a rapid and reliable MS-based diagnostic tool.

4.1.3. Postmortem Sample Proteomics. Lungs are the primary site of entry of the virus. Studying the lung proteome of fatal COVID-19 cases $^{68}$ revealed 637 differentially represented proteins mainly marked by enrichment of neutrophil-related pathways and overexpression of S-100 proteins suggestive of a hyperinflammatory status in severe COVID-19 patients. Interestingly, however, they did not find the virus in the tissue, 

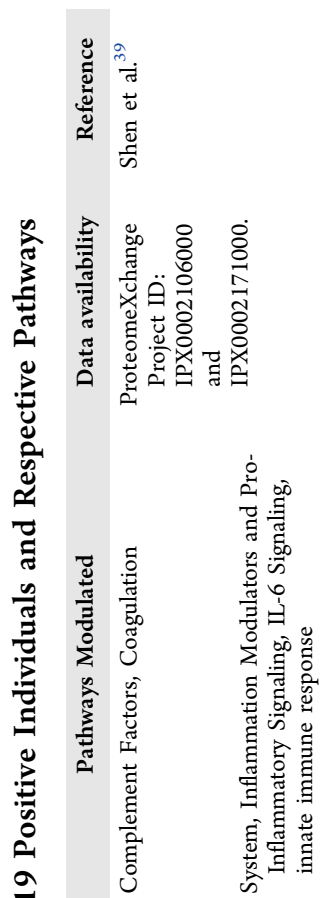

ठิ

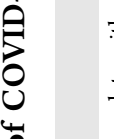

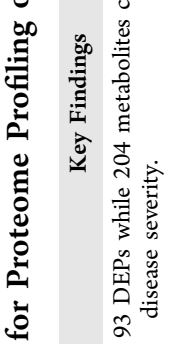
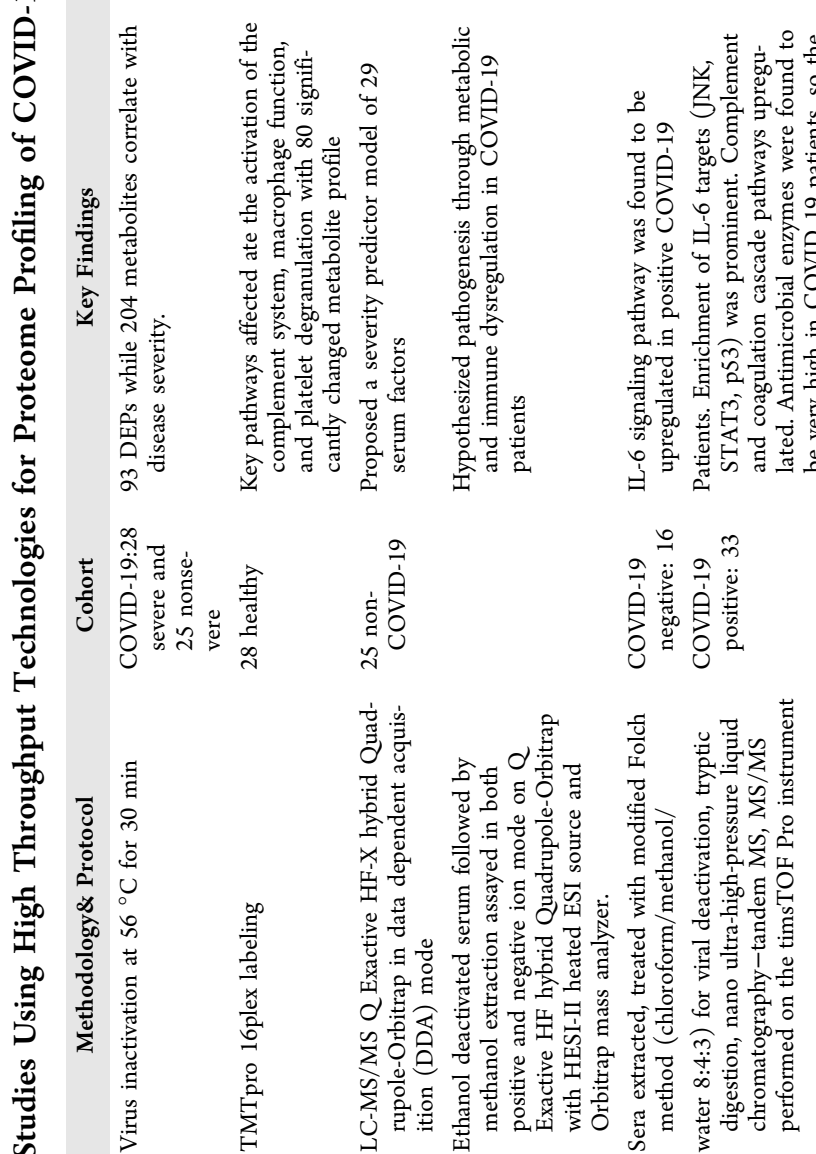

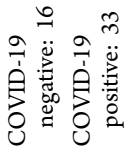
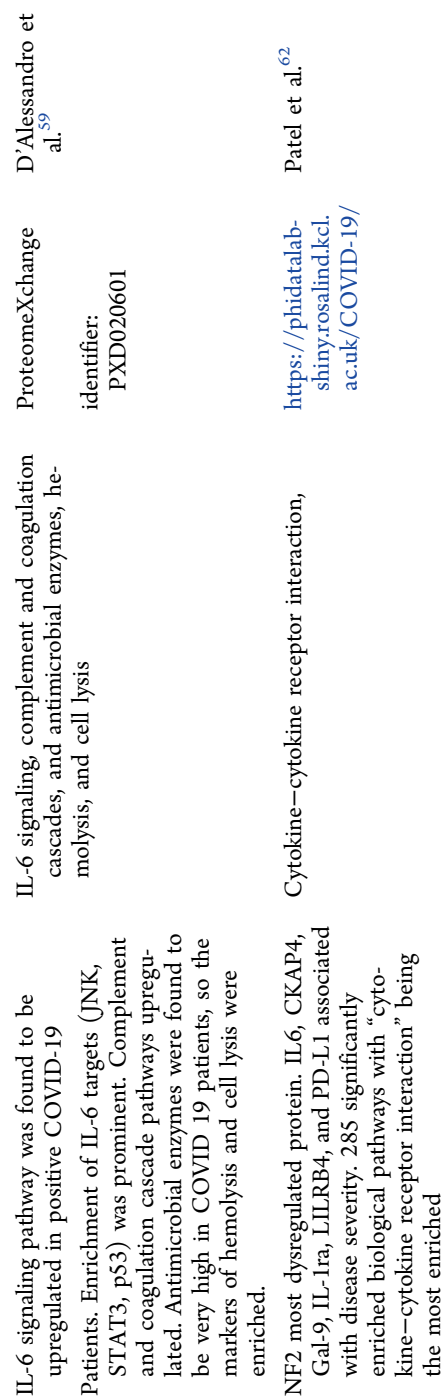

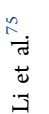

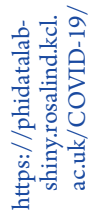

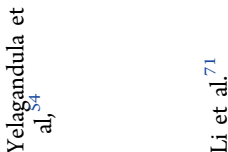

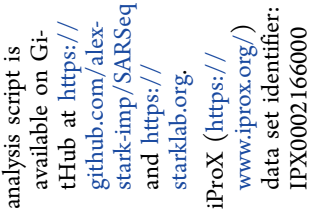
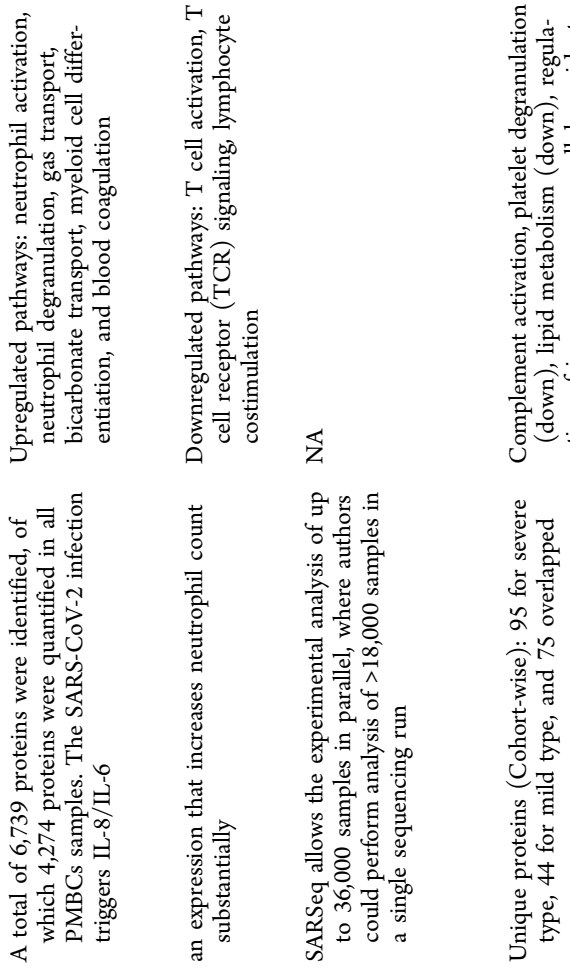

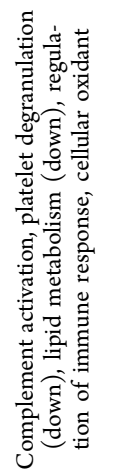

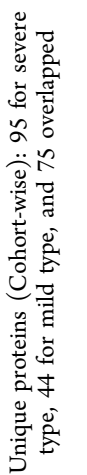

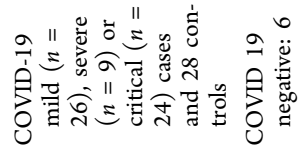

离

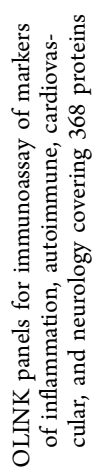

$\stackrel{\circ}{\circ}$
童
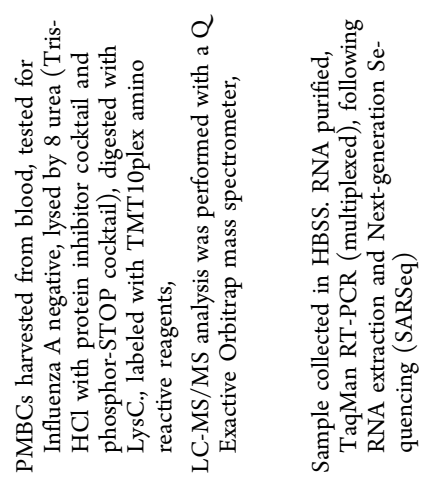

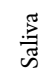

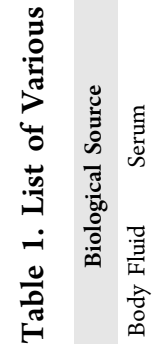

: 


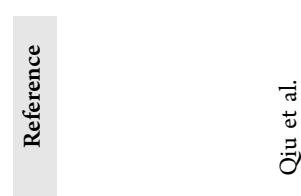

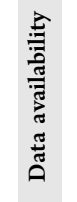

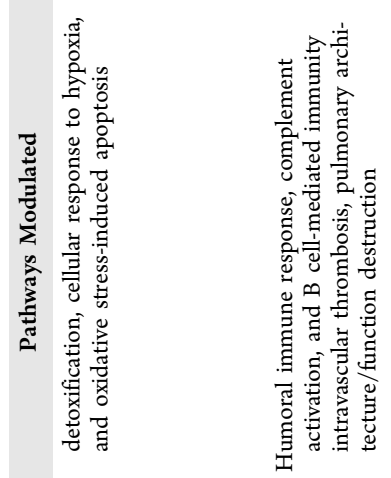

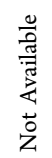

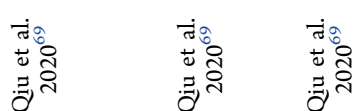

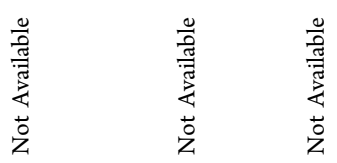

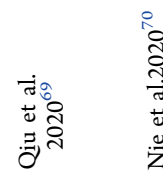

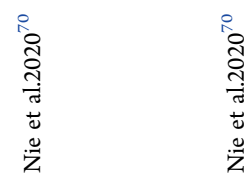

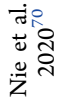
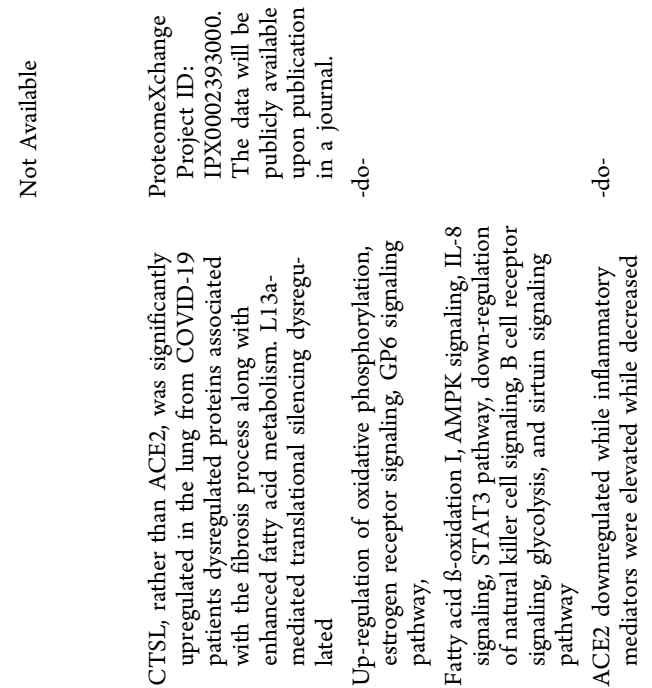

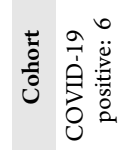

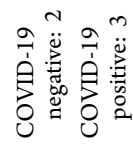

离蒂

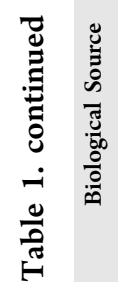

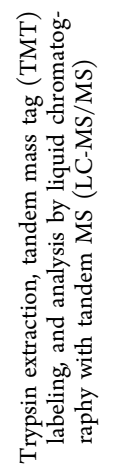

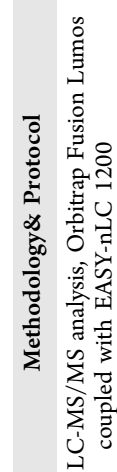

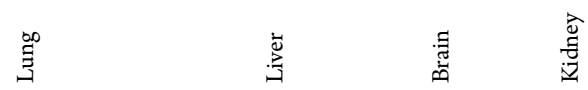

总

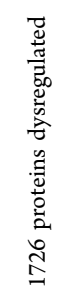

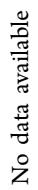

章葛

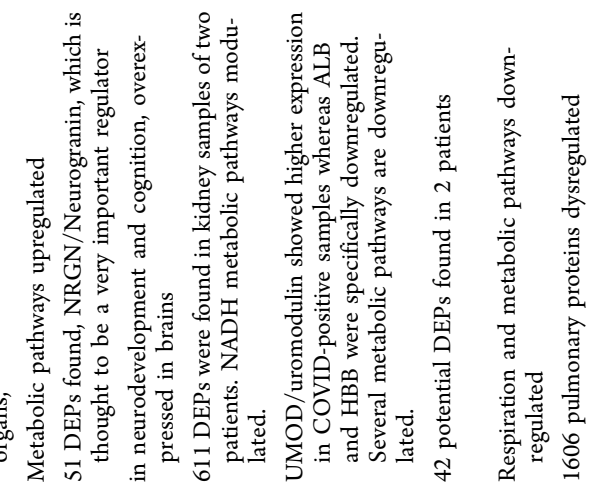

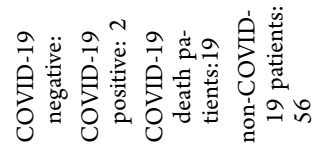

i্t

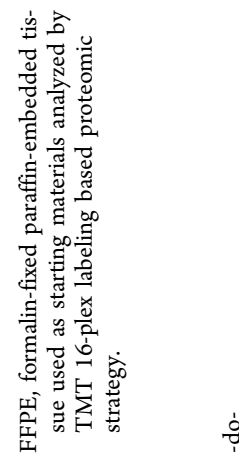

苞苞先

$\frac{5}{\tilde{\varpi}}$

节 


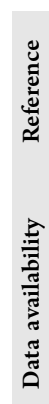
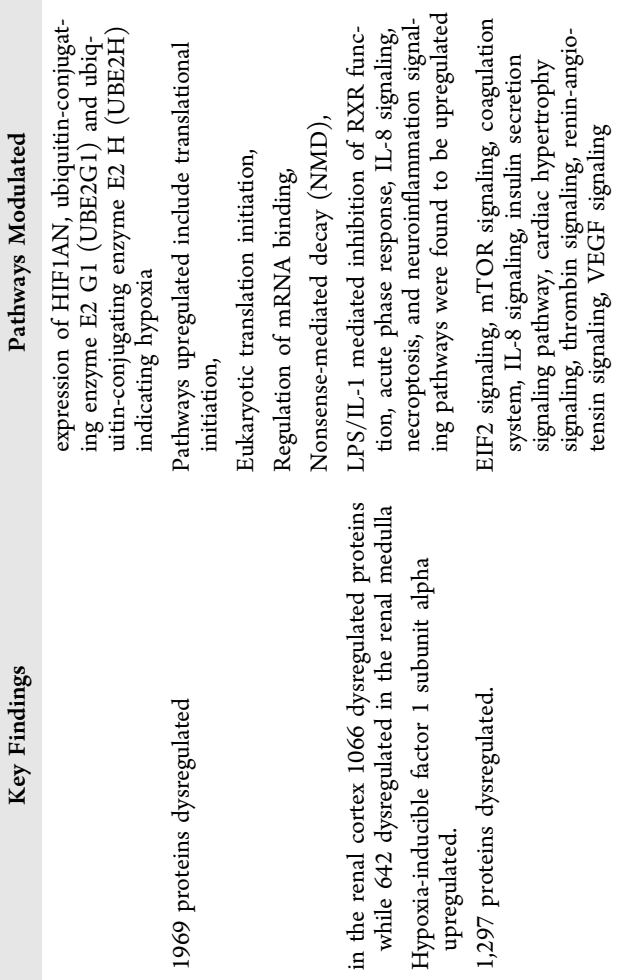

s

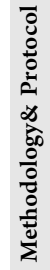

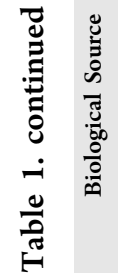

i্ণ

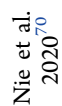

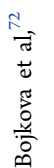
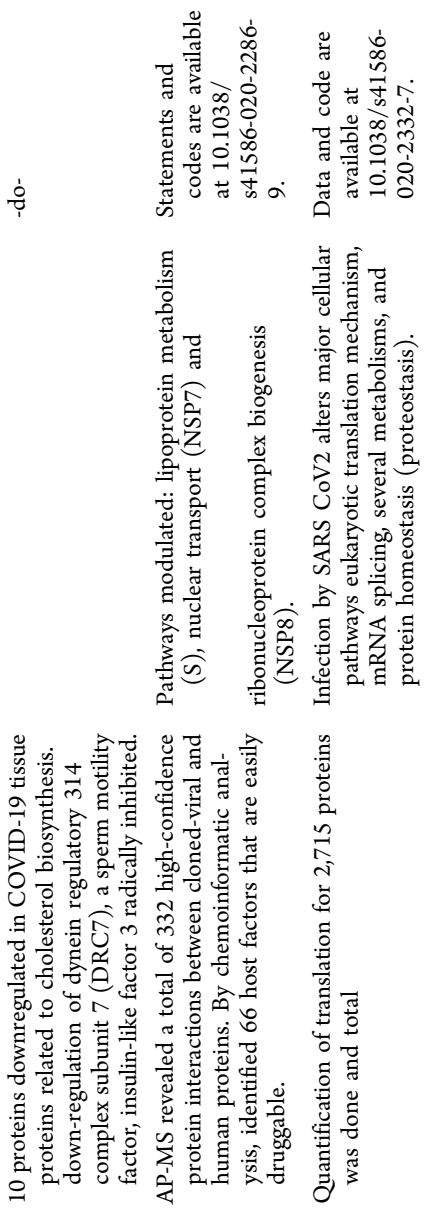

氛

ơ

i़่

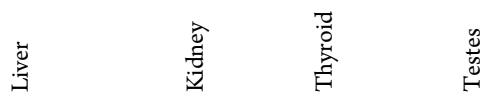

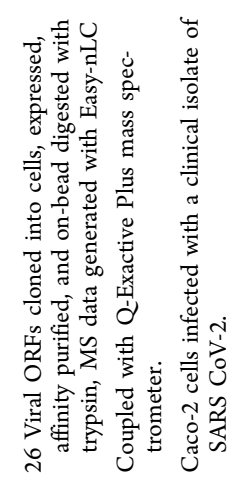

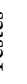

$\stackrel{8}{\dddot{2}}$

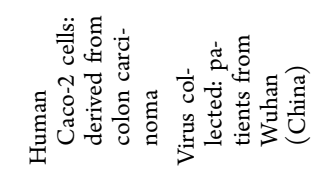

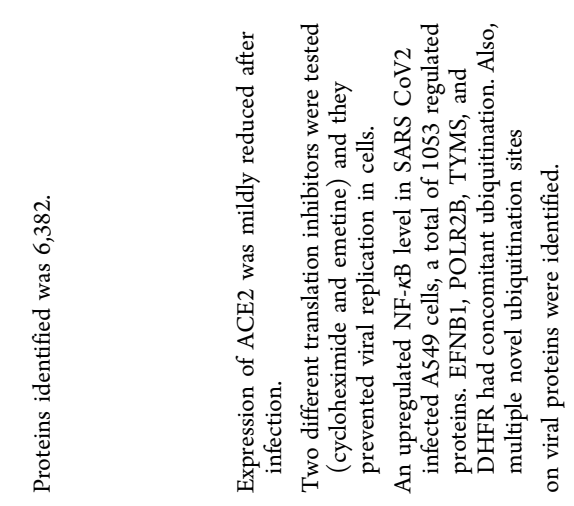

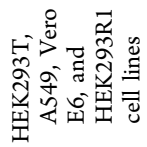

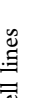

.

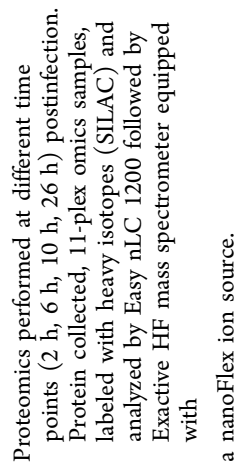

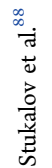

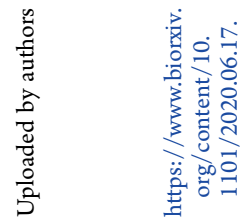

衰 $\overline{\mathrm{g}}$

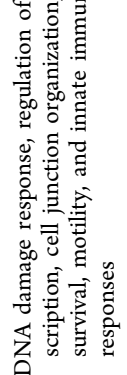

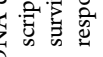




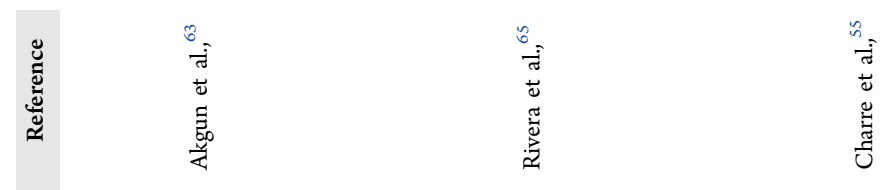

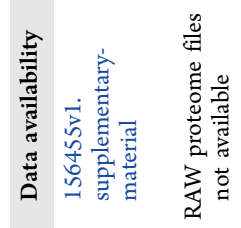

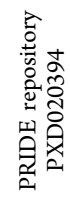

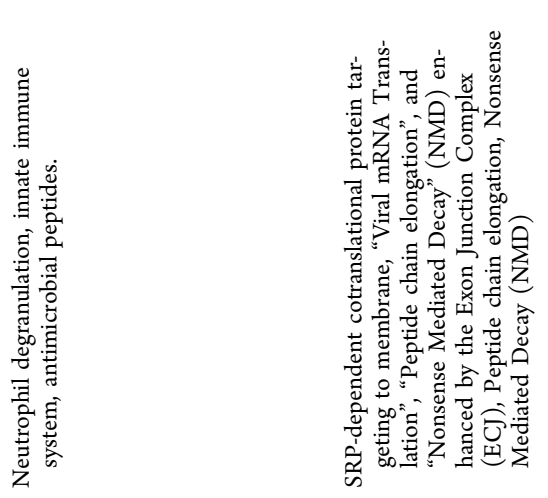

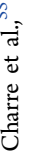

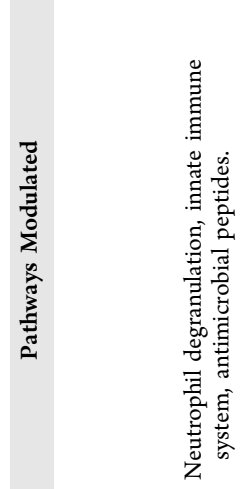

$\overleftrightarrow{Z}$
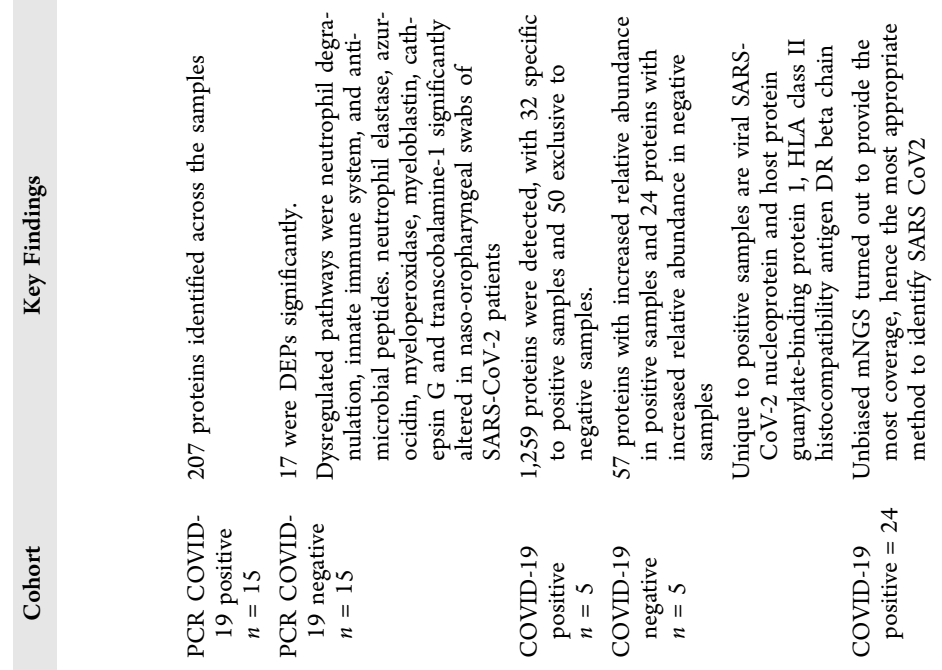

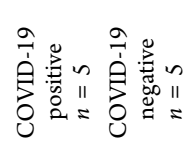

站密
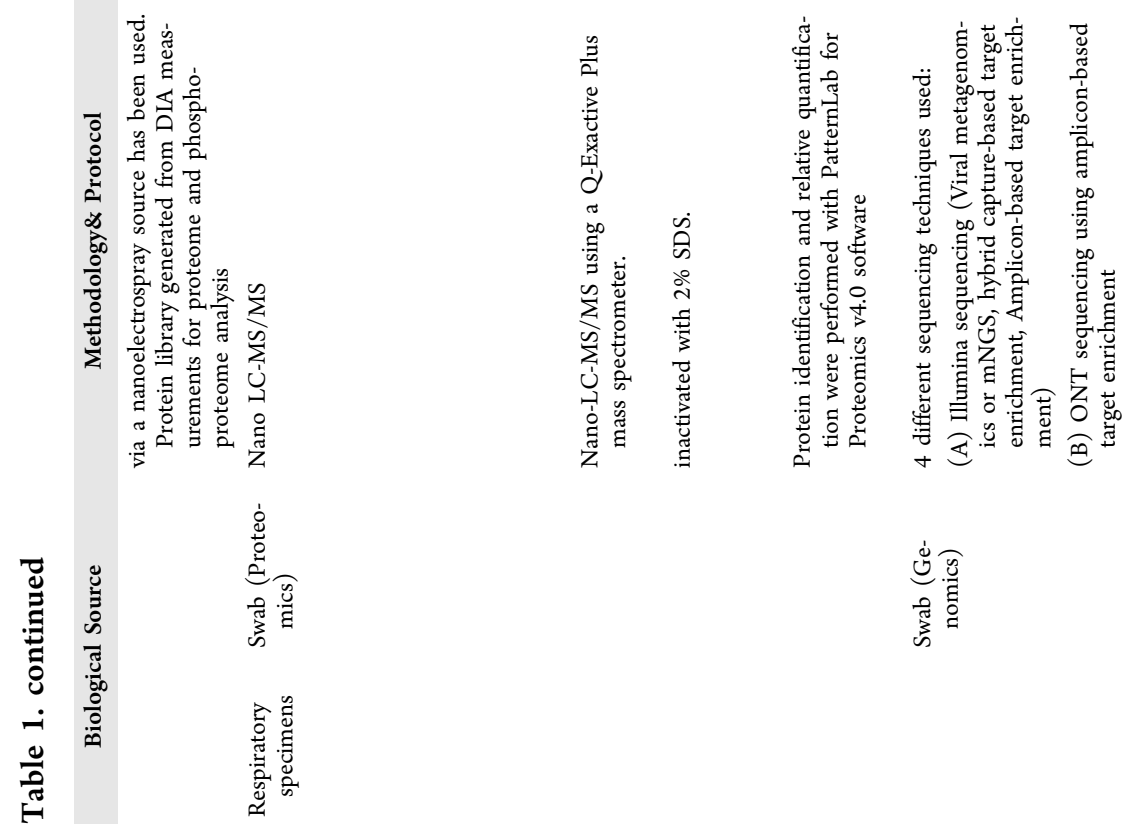

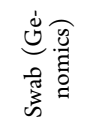


indicating that although the clearance of the virus was achieved, an unruly host response itself was enough to be lethal to patients.

Another study of 8 COVID-19 postmortem specimens generated a comprehensive proteome map of tissues from 8 different organs. ${ }^{69}$ In that study, the authors argued that analyzing postmortem specimens gives the most reliable picture of pathophysiological changes during viral infection. This was based upon them arguing that they had access to all possible regions of lungs using postmortem samples and hence were able to gain a better understanding of tissue pathology. They confirmed almost all immune-related up-regulated pathways (both innate and humoral) in the lungs, whereas pathways contributing to cell cycle maintenance were down-regulated. Other organs such as the liver, kidney, intestine, brain, and heart showed up-regulation of proteins involved in respiration and metabolism (e.g., NADH metabolism, hydrogen peroxide metabolism, and glucose catabolic pathway). In an almost identical approach, the altered proteomic landscape of severe COVID-19 on human tissues was surveyed. ${ }^{70}$ Interestingly, they noticed that, rather than ACE2, it was the CTSL protein that was up-regulated in the lungs. Also, glucose metabolism in the spleen, liver, and kidney was suppressed, as was fatty acid metabolism in the kidney. However, there was an increased fatty acid metabolism in the lung, spleen, liver, heart, and thyroid, along with enhanced protein translation initiation in the lung, liver, renal medulla, and thyroid. Furthermore, functional impairment of Leydig cells and reduced sperm mobility was reported due to down-regulation of cholesterol metabolism, which leads to down-regulation of associated proteins using cholesterol as a precursor. ${ }^{70}$

4.1.4. Urine Proteomics: A study on six urine samples from SARS-CoV-2 infected patients (three mild, three severe) provided insight into possible urine biomarkers that can be used to classify mild from severe symptomology. ${ }^{71}$ A noteworthy observation was that hypoxia up-regulated protein 1 (HYOU1) was 3-fold higher in severe patients compared to mild patients. This protein acts as a part of cellular defense machinery under oxygen deprivation conditions, which is relevant in severe COVID-19 cases where oxygen deprivation and respiratory blockage are common. The patient cohort chosen included 6 COVID-19 positive patients ranging from 58 to 78 years of age, with the three severe cases having dyspnea when samples were collected. The study shows cellular oxidant detoxification in COVID-19 patients' cellular response to hypoxia and oxidative stress-induced apoptosis. Hence, the analysis exhibited a strong response to hypoxic conditions by significant modulation of hypoxia up-regulated protein 1 (HYOU1), which is a defense response against oxygen deprivation. Pathways contributing to lipid metabolism and transport were also down-regulated in severe patients suggesting a blockage in lipoprotein-mediated cholesterol uptake postinfection. On the other hand, cyclic AMP-responsive element-binding protein 3-like protein 3 (CREB3L3) was up-regulated in mild patients. The authors suggested this protein may activate acute phase response (APR) genes as the first line of innate immune protection immediately after infection.

4.1.5. Cell Line Model Proteomic Studies. Additionally, a cell line-based proteomics study was conducted to map the transcriptional and proteome profile of SARS-CoV-2 in a cell line at different time points postinfection. Bojkova et al. found that the pathogen alters the host's vital pathways, including proteostasis, carbon metabolism, nucleic acid metabolism, splicing, and translation. ${ }^{72}$ Further using a similar strategy, 26 viral proteins were expressed in human cells, and affinitypurification MS was used to identify 332 protein-protein interactions between viral and human proteins, potentially altering multiple pathways related to protein trafficking, translation, transcription, and regulation of ubiquitination. These studies further hypothesized that 69 drugs were capable of targeting 66 host proteins and proposed that these should be studied for their ability to ameliorate disease. The same lab reported the altered phosphoproteome of Vero E6 cells ${ }^{74}$ infected with SARS-CoV-2 promoted host p38 MAPK cascade activity and brought about cell cycle arrest by inhibition of mitotic kinases. However, they observed increased CK2containing filopodial protrusions containing the virus.

Another group expressed SARS-CoV-2 proteins in cell lines to elucidate the interactome of the viral proteins with host proteins. ${ }^{75}$ The viral proteins were found to interact with almost 256 host cellar proteins affecting multiple pathways related to essential cellar functioning such as ATP biosynthesis mRNA transport, nucleotide-excision repair, translation initiation, and metabolic processes such as cellular amino acid and reactive oxygen species metabolism. Of particular importance was a finding that implicated the interaction between viral nonstructural protein 10 and NF- $\kappa$ B-repressing factor (NKRF), which in turn induces expression of chemokines such as interleukin-8 (IL-8). Chemokines like IL-8 trigger neutrophil chemotaxis, where these neutrophils reach on-site and release more pro-inflammatory compounds, and as a result, additional inflammatory signals are activated. ${ }^{75,76}$

Various global research groups have been using a range of COVID-19 biospecimens to try to map affected pathways and biomolecular pathways, validating the effect of the pathogen on the host. The various studies have been briefly summarized in Table 1. Proteomics alone may not be sufficient to understand all viral pathobiologies, so investigators have also looked at metabolite profiles of infected hosts using high-throughput technologies.

\subsection{Metabolite Biomarkers}

Metabolomics studies on plasma and serum biospecimens have pointed to alterations in kynurenine, fatty acid, amino acid, ${ }^{77-79}$ nitrogen, ${ }^{77,79}$ pyrimidine, TCA cycle, fructose, and mannose metabolism and guanosine monophosphate (GMP) of nucleotide biosynthesis pathways, carbamoyl phosphate of the urea cycle, and carbon metabolism (Table 2). ${ }^{80}$ Thomas et al. ${ }^{81}$ used serum samples to hypothesize a role for altered fatty acid and kynurenine metabolism in alterations of interleukin-6 (IL-6) levels and its effect on the liver. The group also performed untargeted and targeted metabolomics on serum samples of 33 PCR-confirmed COVID-19 positive patients and 16 COVID-19 negative controls. They reported that tryptophan metabolism was the most affected pathway, followed by aspartate (Asp) and asparagine (Asn) metabolism pathways. In tryptophan metabolism, kynurenine levels were found to be highly overexpressed. Besides, serum gluconeogenic and sulfur-containing amino acid levels were reported to be low while creatinine, acetylspermidine, polyamines spermidine, and creatinine levels were significantly higher in the medium or high IL-6 level group. ${ }^{39,81}$ However, all the patients with COVID-19 were reported to be hyperglycemic irrespective of their IL-6 levels. Interestingly, the group reported nitrogen metabolism modulation as amino acid dysregulation may result in nitrogen metabolism modulation followed by alteration in carbon metabolism. They analyzed glycolytic, TCA, and pentose phosphate pathway substrates and 


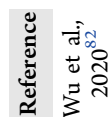

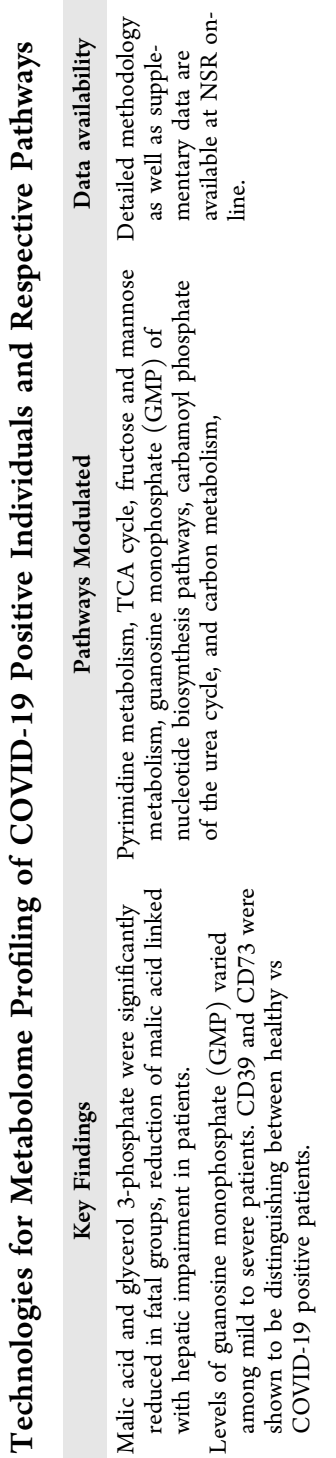

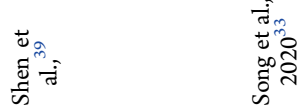

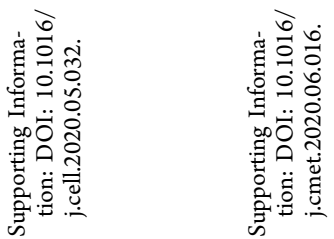

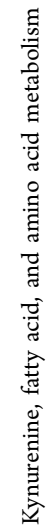

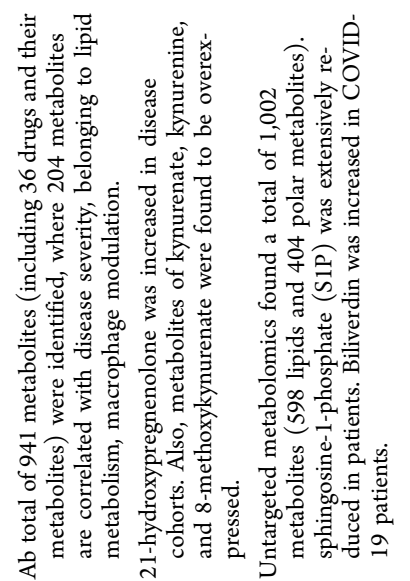

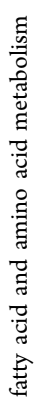

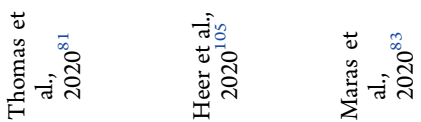
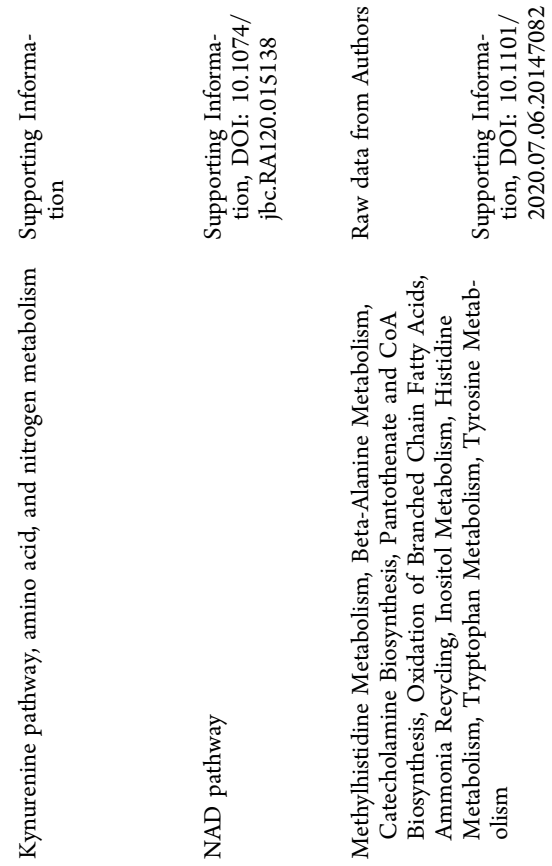
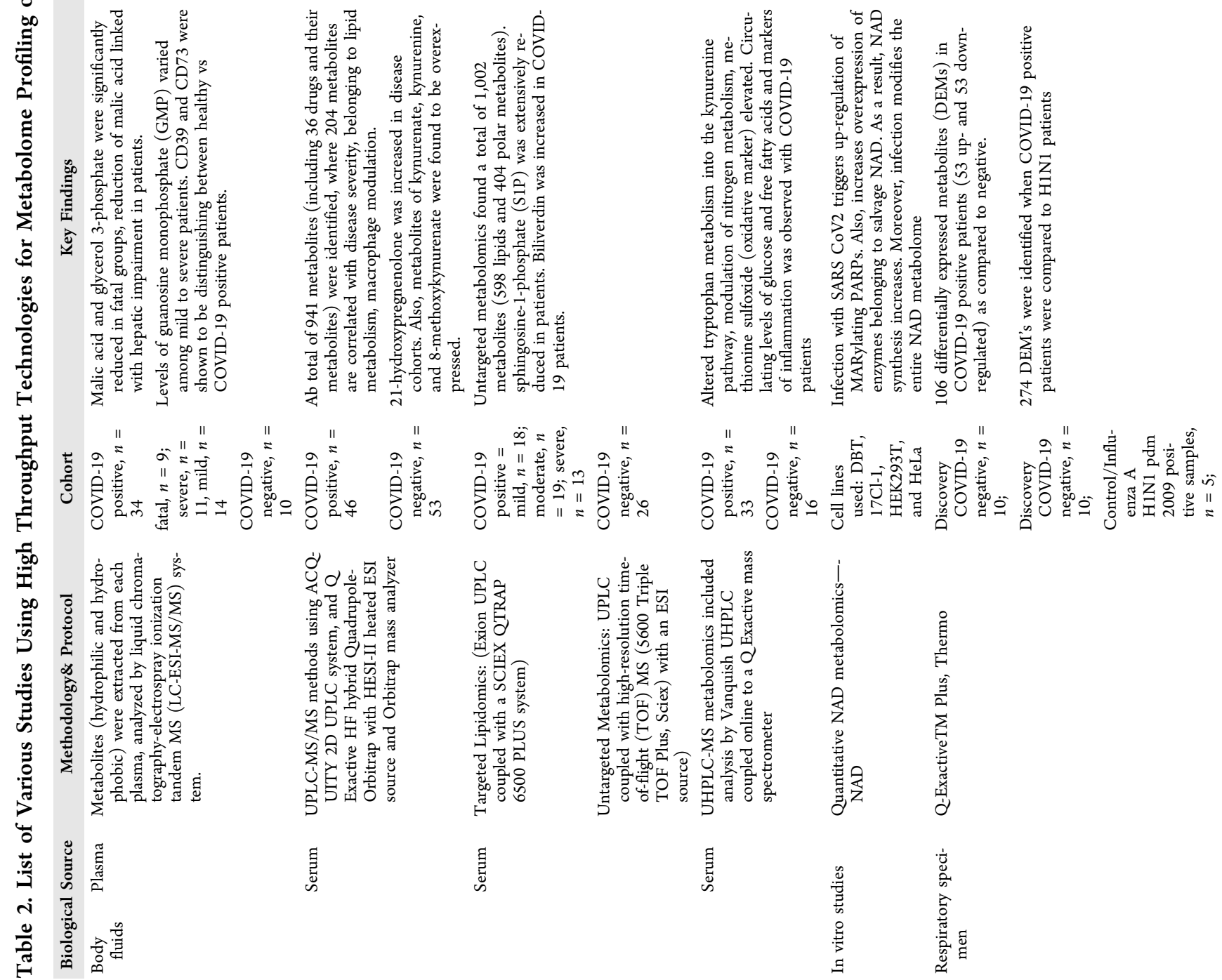
found carboxylic acids remain comparable while $\alpha$-ketoglutarate shows significant upregulation in COVID-19 patients. It is suspected that modulated nitrogen metabolism results in changes in transamination activity as well leading to high $\alpha$ ketoglutarate levels in order to maintain nitrogen homeostasis in patients. High levels of $\alpha$-ketoglutarate might lead to a forward reaction in TCA and may lead to an increased level of glucose and free fatty acids in the bloodstream. In COVID-19 patients, an activated kynurenine pathway is reported to be a result of upregulated pathway components such as kynurenine, 8methoxykynurenate, kynurenate, and phosphocholine, an intermediate metabolite to produce phosphatidylcholine. Also, choline and amino acids along with their derivatives were reported to be down-regulated in severe COVID-19 patients as compared to COVID-19 negative individuals. ${ }^{39}$

$\mathrm{Wu}$ et al. ${ }^{82}$ studied plasma biospecimens and reported that the TCA cycle affected biomolecule malic acid, urea cycle due to carbamoyl phosphate level alteration, and nucleotide biosynthesis due to guanosine monophosphate (GMP) in patients who succumbed to COVID-19. Similarly, Maras et al. ${ }^{83}$ have studied respiratory specimens and reported up-regulation of dopamine, 1-phosphatidyl-d-myoinositol, tyramine-o-sulfate, propionyl carnitine, oleamide, pantothenic acid, l-histidine, azelaic acid, and down-regulation of $N$-acetyl-D-glucosaminyl diphosphodolichol, $\mathrm{N}$-acetylserotonin, and aspartylglycosamine. The alteration of these metabolites results in the alteration of methylhistidine metabolism, beta-alanine metabolism, catecholamine biosynthesis, pantothenate and CoA biosynthesis, oxidation of branched-chain fatty acids, ammonia recycling, inositol metabolism, histidine metabolism, tryptophan metabolism, and tyrosine metabolism. The same study reported that a long SARS-CoV-2 infection favors the chances of bacterial invasion of epithelial cells, which is confirmed by microbiome analysis of respiratory specimens. They were able to map the upregulation of pantothenate and CoA biosynthesis linked enzymes related to Actinobacter species.

Jin-Wen Song et al. performed MS-based analysis on plasma for lipid and polar metabolite profile comparison of COVID-19 positive patients compared to control, COVID-19 negative individuals. The group reported a significant reduction in lymphocyte counts and a significant increase in the levels of $\mathrm{C}$ reactive protein (CPR), interleukin 6 (IL-6), pro-calcitonin, and serum ferritin (SF) in COVID-19 positive patients. They also reported a panel of 10 metabolites namely LPA 18:1, SM d18:1/ 18:1, S1P d18:1, lysoPC18:1, TAG60:3(18:1), biliverdin, GM3 d18:1/25:0, TAG 48:1(18:0), 5-hydroxy-L-tryptophan, and DAG34:1(16:1/18:0) for differentiating between COVID-19 positive and negative patients with 0.975 area under the ROC curve (AUC). ${ }^{33}$ These panels of candidate metabolites can be validated further for COVID-19 diagnosis and prognosis.

Reports from various research groups suggest that $\mathrm{NAD}+$ synthesis regulates macrophage activation, which in turn modulates a pro-inflammatory response. ${ }^{84,85}$ Hence, Collin et al., $^{86}$ validated one of the major pathways, namely NAD metabolism, altered in COVID-19 patients using human lung cell lines. They reported dysregulation of synthesis and utilization of nicotinamide adenine dinucleotide (NAD). The genes contributing to this perturbation of the NAD metabolism were up-regulated, exhibiting expression of PARP isoforms such as PARP10, a member of the poly(ADP-ribose) polymerase (PARP) family. They also reported decreased replication of the $\beta$-coronavirus murine hepatitis virus (MHV) infected model, sensitive to PARP activity, by the activation of nicotinamide 
phosphoribosyltransferase (NAMPT), nicotinamide (NAM), and nicotinamide riboside (NR). ${ }^{86}$ Metabolomics studies have facilitated a better understanding of COVID-19 pathobiology. Successful clinical translation of these metabolomic markers requires extensive validation.

\section{HOST INNATE AND ADAPTIVE IMMUNOLOGICAL RESPONSES TO SARS-COV-2}

The diseased state elicits a strong innate immune response as well as an adaptive immune response. Since the emergence of COVID-19 as a global pandemic, studies centered on the immune response evoked postinfection have been a major area of interest to scientists. However, unlike in previous pandemics, where technological limitations impeded the generation of new knowledge, the advent of omics-based high-throughput technologies has enabled scientists to generate a rapid and unprecedented overview of the biochemistry of the immune response to infection. Innate immune responses are the frontline, nonspecific defenses that not only act against invading pathogens but also assist in triggering highly specific adaptive immune responses. Innate immune responses act as an early warning system to thwart severe infection. SARS-CoV-2 triggers a cascade of molecules linked to the innate immune system, which could be detected using omics technologies.

\subsection{Innate Immune Response}

MS-based proteomics discovery on COVID-19 serum and plasma has provided novel biomarkers of immune responses, especially the innate immune response. Two comprehensive studies on the proteome of patient sera explicitly implicate the overactivation of the complement system, which is an effector component of both adaptive and innate immunity as a hallmark of COVID-19. In a study on a Chinese cohort of 46 patients Shen et al. ${ }^{39}$ reported the up-regulation of complement system proteins $\mathrm{C} 5, \mathrm{C} 6$, and $\mathrm{C}$ and their regulators' properdin (CFP) and carboxypeptidase $\mathrm{N}$ catalytic chain (CPN1). Further, because of complement system activation in severe patients' serum mannose and its derivatives were significantly higher. An almost concurrent study by Messner et al. ${ }^{61}$ on 31 hospitalized COVID-19 patients also reported activation of the classical complement pathway, namely $\mathrm{C} 1 \mathrm{R}, \mathrm{C} 1 \mathrm{~S}$, and $\mathrm{C} 8 \mathrm{~A}$, besides the alternative pathway factor $\mathrm{B}(\mathrm{CFB})$ and the complement modulators such as factors $\mathrm{CFI}$ and $\mathrm{H} \mathrm{CFH}$.

Inflammation is another attribute of activation of the innate immune system. In COVID-19 plasma, Messner et al. ${ }^{61}$ reported the up-regulation of several proteins implicated in IL-6 signaling, namely, serum amyloid A1 and A2, interalpha-trypsin inhibitor heavy chain 4, haptoglobin, leucine-rich alpha-2-glycoprotein, monocyte differentiation antigen cd14, and galectin 3 binding protein. Proteomics of PBMCs isolated from COVID-19 patients $^{62}$ also demonstrated a clear up-regulation of CXCR2, PRG3, LBP, MMP25, CRP, and NLRP1, indicating the activation of the IL-6/IL-8 directed innate immunity inflammation pathway in mild cases of COVID-19. Proteomics of COVID-19 serum stratified by rising levels of the cytokine IL-6 has determined that the complement factors H I and C5 were up-regulated implicating complement system activation; this positively correlated with enhanced IL-6 levels. ${ }^{59}$ Further, lung autopsy samples of patients deceased due to COVID-19 have revealed that the indicators of innate immune response TNF receptor-associated factor 6 (TRAF6), TYRO protein tyrosine kinase binding protein (TYROBP) were up-regulated, as were factors responsible for the pro-inflammatory state. ${ }^{70}$
Few in vitro studies reveal the interactome of the viral protein in human cell lines. Biotin-streptavidin based affinity MS studies showed that the viral protein ORF $9 \mathrm{~b}$ physically interacts with mitochondrial protein TOM70 to inhibit IFN-I responses of the host. ${ }^{87}$ Given that interferon signaling forms a vital part of innate antiviral host defense, these results indicate that the virus can evade the immune system.

Gordon et al. used affinity-purification MS on HEK-293T/17 cells $^{13}$ expressing viral proteins to show that the SARS-CoV-2 proteome targets many innate immune signaling pathways. NSP13 targets the interferon pathway by interacting with TBK1 and TBKBP, while NSP15 targets RNF41 and ORF9b targets TOMM70. Moreover, the NF- $\kappa$ B pathway is targeted by NSP 13 with its interactors TLE1, TLE3, and TLE5 along with ORF9c, which shows interaction with NLRX1, F2RL1, and NDFIP2. Two E3 ubiquitin ligases regulate antiviral innate immune signaling, TRIM59 and MIB1, by ORF3a and NSP9, respectively.

In another in vitro investigation, Stukalov et al. expressed 54 individual viral proteins in lung carcinoma A549 cells, followed by whole proteome analysis. ${ }^{88}$ They reported that factors known to modulate innate immune responses after virus infection, like TGF $\beta$ and EGFR pathways, were up-regulated. Primarily, it is SARS-CoV-2 viral proteins $\mathrm{M}, \mathrm{ORF} 3$, and ORF7b that target several key cellular regulators involved in innate immunity. Furthermore, SARS-CoV-2 inhibits interferon signaling pathways that take part in antiviral host defense. Interferon production is inhibited by viral proteins ORF3, ORF6, ORF7a, ORF7b, and ORF9b. These observations were further substantiated by the dose-dependent inhibition of virus replication in SARS-CoV-2 infected A549-ACE2 cells upon IFN $\alpha$ treatment in vitro.

There is a lack of proteomics studies on the longitudinal profile of patients, especially studies focused on innate immune markers. Although innate immune markers are the classical early response defense mechanism, longitudinal studies on a mild versus severe COVID-19 cohort, especially in the convalescent phase, would clearly define the long-term impact of COVID-19 on innate immune markers. This is especially relevant since these signaling molecules can have deleterious consequences on human health.

\subsection{Adaptive Immune Response}

While the innate response is hard-wired into the human genome and the mode of action is rather broad, an adaptive immune response is gained only after an encounter with the pathogen or its components either via infection or exposure to vaccines. However, with this tradeoff comes the pinpoint accuracy of adaptive immunity, which confers pathogen-specific protection to the host. The adaptive response can be either cell-mediated, which is carried out by $\mathrm{T}$ cells, or a humoral immune response, which is controlled by activated B cells and antibodies. SARS$\mathrm{CoV}-2$, being a novel coronavirus in humans, has no present-day adaptive immune countermeasures, hence the rush for production of vaccines against COVID-19.

Proteomics of PBMCs isolated from mild and severe COVID19 patients $^{62}$ has revealed hitherto unknown aspects of infection. Compared to moderately symptomatic cases, expression of $\mathrm{T}$ cell receptor (TCR) subunits (CD3e, CD3g, CD247, TRAC, and TRBC1), T cell surface molecules (CD4, CD8a, CD8b, and CD2), MHC class II molecules (HLA-DRA, HLA-DRB1, HLA-DRB4, and HLA-DRB5), $T$ cell migration stimulators (DDP4), and TCR signaling kinases (ZAP70, LCK, 

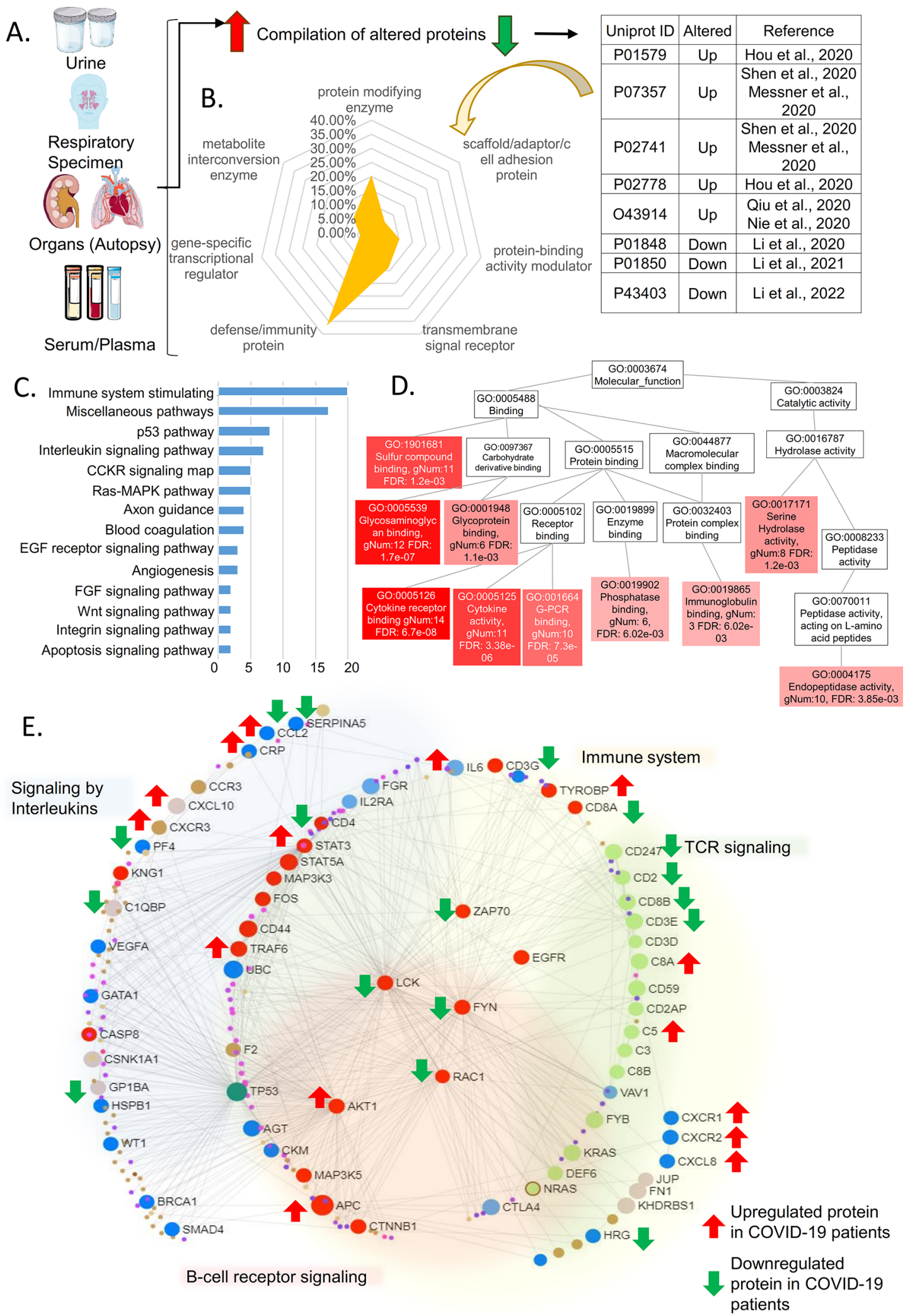

Figure 3. Proteomics study and understanding of affected pathways. (A) Workflow used in the proteome profiling of the COVID-19 patients as compared to negative individuals to understand altered pathways. (B) Enrichment of altered proteins as per their protein groups. (C) Enrichment of altered proteins in various pathways in COVID-19 positive patients. (D) Enrichment of altered proteins on the basis of their molecular function. (E) Pathway analysis of all the significantly altered proteins reposted in various research articles. Red upward arrow represents upregulated proteins, and green downward arrow represents downregulated proteins. This figure was created using Servier Medical Art templates, which are licensed under a Creative Commons Attribution 3.0 Unported License; https://smart.servier.com. 
and FYN) was significantly reduced in severe COVID-19. This observation points to a collapse of $\mathrm{T}$ cell activation and function. Likewise, immunoglobulin subunit expression (IGHG1, IGHG2, IGHG4, IGLC2, IGLL1, and IGHE) was reduced in severe cases, implying diminished antibody secretion by B cells. Therefore, severe COVID-19 patients suffer functional declines in various aspects of adaptive immunity, which also corresponds with their poor T cell and B cell populations. However, MS of COVID-19 serum showed protein components of immunoglobulins increased, especially levels of heavy and light variable regions and light chain constant regions, which sometimes positively correlated with IL-6 levels. ${ }^{39}$ An in-depth study on autopsy samples by Nie et al. provides a descriptive picture of the onslaught of severe SARS-CoV-2 infection. The body's adaptive defenses appear to bear the brunt of the virus. Their study showed up-regulation of immune checkpoint proteins CEACAM1, CD276, and CD274 that lead to suppression of adaptive immune function. $^{70}$

In a SARS-CoV-2 proteome microarray covering 18 out of 28 putative viral proteins, sera IgG and IgM antibody responses from 29 convalescent patients were studied. Data indicated seroconversion of IgG and IgM antibodies that specifically bind SARS-CoV-2 proteins was absolute. However, viral N, S1, ORF9b, and NSP5 proteins were strongly immunogenic. Further, the study found that S1-specific IgG positively correlates with age and level of lactate dehydrogenase (LDH) and inversely correlated with lymphocyte cell percentage. ${ }^{89} \mathrm{~A}$ comparable investigation employing an in-house microarray that contained chemically synthesized, linear peptides of full-length $\mathrm{N}$ protein, full-length $\mathrm{E}$ protein, five truncated $\mathrm{S}$ proteins, and 966 tiled peptides representing the SARS-CoV-2 proteome ${ }^{90}$ reported comparisons between early stage COVID-19 patients and noninfluenza patient groups. The study described 76 IgM and 17 IgG antigens that were differentially targeted. IgM was against $S$ protein, specifically $S 1, S 1 R B D, S 1+S 2 E C D, S 2 E C D$, as well as $\mathrm{N}$ protein, $\mathrm{M}$ protein, E protein, Orf1ab, Orf3a, Orf6, Orf8, and Orf10. IgG immunogenicity was specified to react against $S$ protein, namely S1, S1RBD, S1+S2ECD, and S2ECD besides $\mathrm{N}$ protein, $\mathrm{E}$ protein, and Orflab. An exhaustive evaluation revealed that barely $27 \mathrm{IgM}$ and $9 \mathrm{IgG}$ antigens were exclusive to COVID-19. These IgM antigens were from the $S$ protein (22 peptides, S1, S1RBD, S1+S2ECD, and S2ECD. Since SARS-CoV-2 exhibits $S$ protein across the virus surface, and this is readily accessible to the humoral immune system during early infection, IgM antibodies targeting the $S$ protein are produced. IgG antigens were from the $S$ protein (2 peptides, S1RBD, S1+S2ECD, S2ECD), N protein (2 peptides, full-length protein), and Orflab (1 peptide), hinting that as the virus proliferates within host cells, the $\mathrm{N}$ and Orflab proteins could leak from cells and subsequently be recognized by the humoral immune system.

Employing a targeted proteomics approach, a high-density antibody microarray of 532 antibodies was used to detect serum proteins from the initial stages of COVID-19 or influenza. The investigation $^{60}$ determined that 125 proteins exhibited differential expression that includes 88 up-regulated and 37 downregulated proteins. Interestingly, an increase in cytokines (IFNG, IL6, CXCL8, CXCL10, and CCL2) was noted in moderate and severe COVID-19 patients. Further, signaling pathways involved in cytokine-cytokine receptor interaction, cytokine signaling in the immune system, IL-4 and IL-13 signaling, IL-17 signaling, and JAK-STAT, MAPK, and PI3KAkt signaling were highly up-regulated. Using whole SARS-
CoV-2 proteome peptide microarrays, ${ }^{91}$ one team tested serum samples for SARS-CoV-2-specific IgA, IgG, and IgM antibodies. They noted that shortly after disease onset a clear SARS-CoV-2specific IgA response was noted in moderate cases, while severe cases exhibited a delayed but ultimately extremely intense and comprehensive SARS-CoV-2-specific IgA response.

On the other hand, de Assis et al. used an antigen microarray that contained antigens from a broad array of respiratory viruses including SARS-CoV-2 using SARS-CoV-2 convalescent sera and that collected before the COVID-19 pandemic. The SARSCoV-2 sera demonstrated higher IgG reactivity than for IgA while the prepandemic sera could only elicit strong reactivity to common cold coronavirus antigens. ${ }^{92}$

As discussed previously, the NGS approach helped in profiling adaptive immunity in patients against COVID-19 both during active infection or during convalescence. ${ }^{57} \mathrm{~B}$ cells displayed converging IGHV3 and IGHJ4/6 guided BCR clusters linked to SARS-CoV-2 antibodies, and most lacked somatic hypermutation, an indication of a naive response rather than a targeted response to infection. Moreover, patients with severe COVID-19 showed a significantly poorer percentage of $\mathrm{B}$ lineage cells carrying an unmutated BCR indicating the weak humoral response in severe COVID-19. However, it remains to be determined if this is a cause or effect of disease severity. Also, the authors noted the emergence of $\mathrm{T}$ cell clusters in convalescent COVID-19 patients.

\section{INTEGRATED ANALYSIS OF OMICS DATA}

With the wide-ranging studies available today, we conducted a meta-analysis of information available to provide an integrated view of perturbations in host responses at both the proteome and metabolome levels.

\subsection{Methodology}

A literature review was conducted on published or preprint studies up until 9/27/2020. Search words were ("coronavirus", "severe acute respiratory syndrome coronavirus 2", "COVID-19 proteome profiling", "COVID-19 metabolome profiling”, "COVID-19 metabolite alterations", "Proteomics and COVID19", "Metabolomics and COVID-19", "SARS-CoV-2", OR "COVID-19"). The selected studies include all the clinical variations and culture-based studies. The significantly altered metabolites and proteins were selected for the COVID-19 positive as compared to the COVID-19 negative group, and altered pathways were mapped. The mapping scores are statistical scores that include the sum of enrichment scores and the frequency of significant metabolites clustering together.

\subsection{Proteomics Metadata Analysis}

All the research and review articles covering clinical, cell-based and postmortem studies were compiled to obtain the list of significant proteins in the COVID-19 positive compared to the COVID-19 negative control group (Figure 3A). Significant proteins were selected for $p \leq 0.05$ and fold change $\geq 2$ (Supplementary Table S1). The list of proteins was further used to search for gene name, and mapped gene names were further taken to map the proteins in various protein groups, pathways, and molecular functions to understand their role in COVID-19 pathology (Figure 3B, C, and D, respectively). The proteins were also analyzed for protein-protein interaction in significantly altered pathways and alteration trends mapped on respective pathways (Figure 3E). 
A.

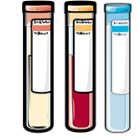

Serum/Plasma

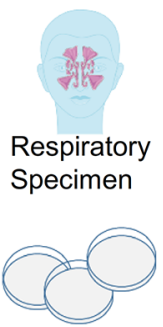

Infected Human cell line

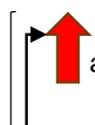

altered metabolites

altered metabolites

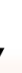

HMDB ID Altered Reference

HMDB0000073 Up Maras et al., 2020

Shen et al., 2020

Song et al., 2020:

HMDB0000684 Up Thomas et al., 2020

Shen et al., 2020;

HMDB0001406 Up Heer et al 2020

Shen et al., 2020

HMDB0000148 Down Song et al., 2020

HMDB0001138 Down Shen et al., 2020

HMDB0001488 Down Heer et al., 2020

HMDB0000064 Down Shen et al., 2020;

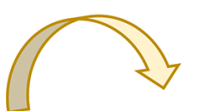

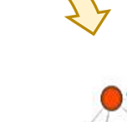

Oarcosiss

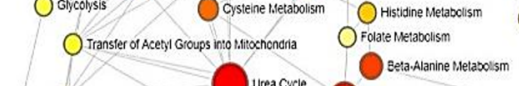

Octre Adid Cycti

Ominocher

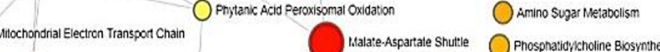

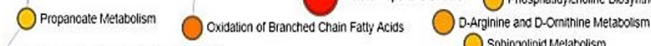

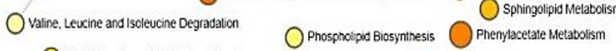

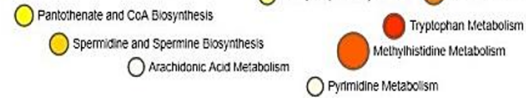

C.
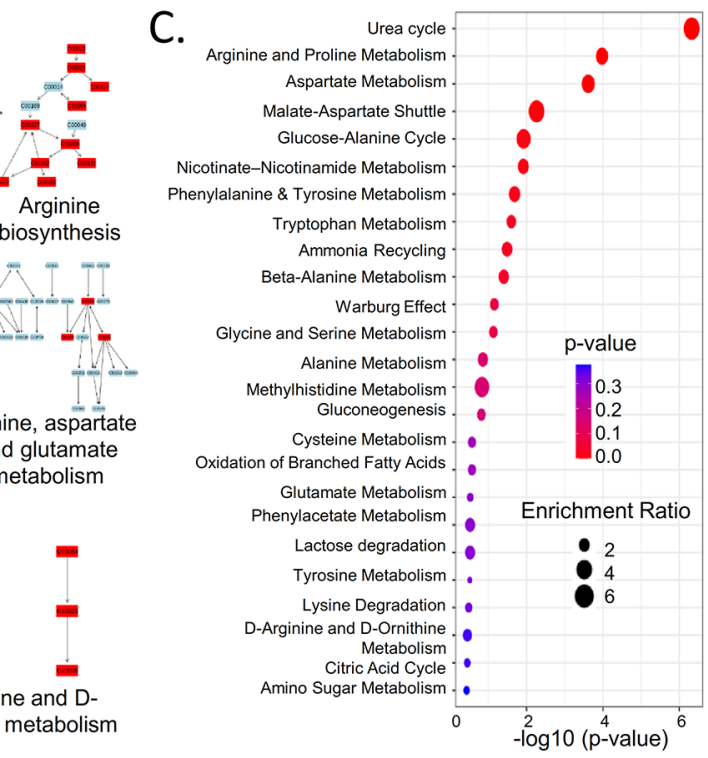

biosynthesis

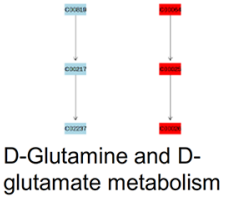

B.

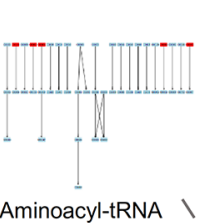
Aminoacyl-tR
biosynthesis

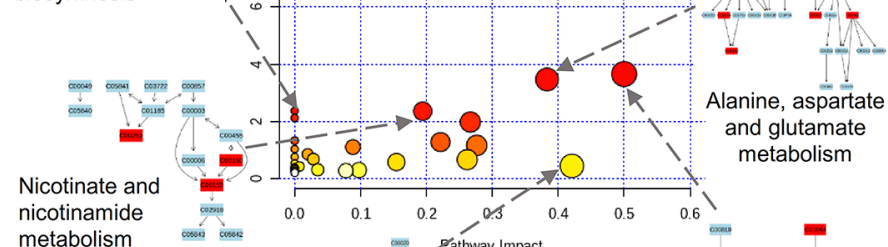
metabolism
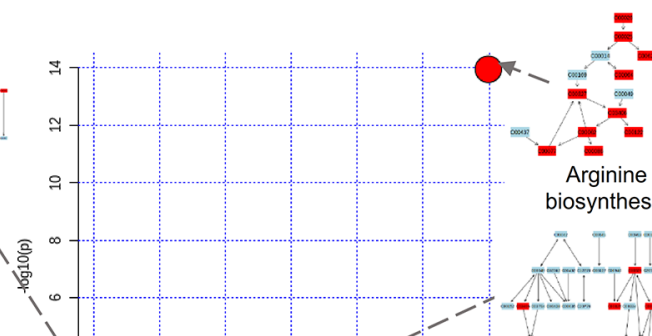
Starch and sucrose

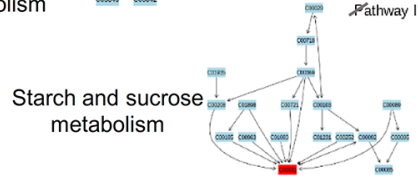

D.

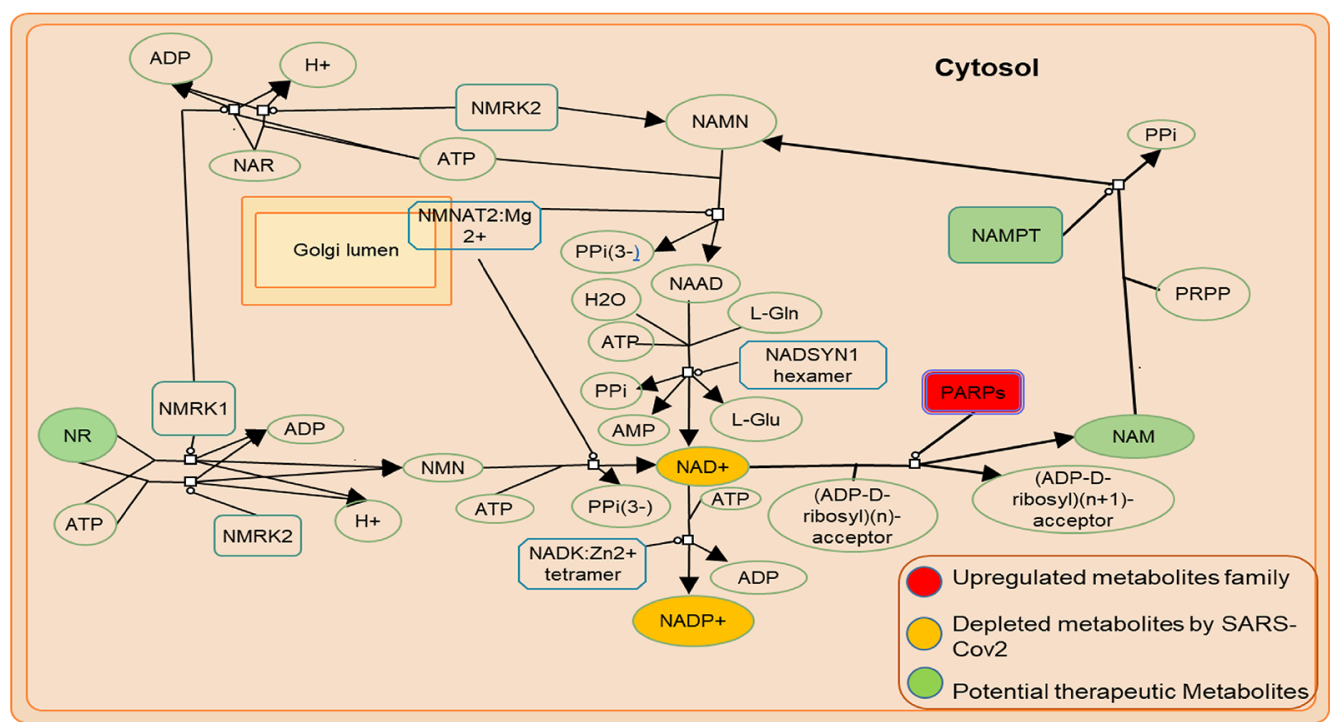

Figure 4. Metabolomics study and understanding of affected pathways. (A) Workflow used in the metabolome profiling of the COVID-19 patients as compared to negative individuals to understand altered pathways. (B) Altered metabolite profiling of COVID-19 positive patients, depicting metabolite pathways altered in COVID-19 patients with $-\log 10(p)>2$. (C) Enrichment of metabolites in various pathways of COVID-19 positive patients. (D) Depicting the NAD pathway effected due to SARS-CoV-2 for its survival (Heer et al., 2020). Red metabolite represents the upregulated protein family, effecting NAD+ and NADP+ (Yellow). This depletion can be nourished with nicotinamide phosphoribosyltransferase (NAMPT), nicotinamide (NAM), and nicotinamide riboside (NR) supplements. This figure was created using Servier Medical Art templates, which are licensed under a Creative Commons Attribution 3.0 Unported License; https://smart.servier.com. 


\subsection{Metabolomics Metadata Analysis}

All the research and review articles covering the clinical and cell line-based studies were compiled to obtain the list of significant metabolites in the COVID-19 positive group when compared to the COVID-19 negative control group (Figure 4A). The list of significant metabolites was taken, and their HMDB, PubChem, and KEGG IDs were mapped. Using mapped IDs, we tried to enrich the metabolites to understand which metabolites cluster together in pathways. This was followed by pathways analysis (Figure 4B and 4C).

\subsection{GO Pathways Analysis}

Altered proteins and metabolites from all studies were compiled and analyzed ${ }^{93-104}$ to understand pathways affected. All altered proteins reported were compiled and data analysis undertaken. Proteins were enriched under three categories, namely protein groups, molecular function, and pathways involved (Figure 3 and Table S1). The majority of proteins mapped to response to stimulus category of biological processes, belonging to the membrane component of cell and molecular function of protein binding as per gene ontology analysis (Figure S1). Pathway analysis was also done using all altered proteins. This resulted in four significant pathways being affected, namely the immune system, TCR signaling, B-cell receptor signaling, and signaling by interleukins. Up-regulated and down-regulated proteins were mapped onto pathways, where red arrows represent upregulated proteins and green arrows represent down-regulated proteins (Figure 3E).

All the altered metabolites were compiled and enrichment analysis performed using pathway-associated metabolite sets containing 99 metabolite sets derived from normal human metabolic pathways. The enrichment was done by mapping $\geq 2$ metabolites in the process, with the highest score coming from the urea cycle followed by arginine and proline metabolism. Also, pathway analysis was done using Fisher's Exact test-based over-representation analysis (ORA) to note the pathways affected due to these altered metabolites being analyzed and five majorly altered pathways being found with FDR value $<0.1$, $-\log 10(\mathrm{p})>2$, and holm adjusted $\mathrm{p}$-value $<0.3$. These pathways include arginine biosynthesis, D-glutamine and Dglutamate metabolism, alanine, aspartate, and glutamate metabolism, aminoacyl-tRNA biosynthesis, and also nicotinate and nicotinamide metabolism (Figure 4, Table S2, and Figure S2). One research group performed a metabolomics study on human lung cell lines. They reported proteins of the PARP family lead to pathogenesis in COVID-19 by utilizing cellular NAD for its survival and suggested that enhancing NAD-based defenses might boost innate immunity ${ }^{105}$ (Figure 4D).

\subsection{Integration of Proteomics and Metabolomics}

The list of significant proteins and metabolites was used to map common pathways that might be altered in diseased conditions. These lists were subjected to Cytoscape, and data were analyzed for pathways mapping using compound-reaction-enzyme-gene network type. Various pathways were mapped, such as amino sugar metabolism, androgen and estrogen biosynthesis and metabolism, fructose and mannose metabolism, galactose metabolism, glycerophospholipid metabolism, glycine, serine, alanine, and threonine metabolism, histidine metabolism, Nglycan biosynthesis, phosphatidylinositol phosphate metabolism, purine metabolism, pyrimidine metabolism, TCA cycle, tryptophan metabolism, tyrosine metabolism, urea cycle and metabolism of arginine, proline, glutamate, aspartate and asparagine, vitamin B3 (nicotinate and nicotinamide) metabo- lism, vitamin B5 - CoA biosynthesis from pantothenate, and vitamin B9 (folate) metabolism. Out of these, androgen and estrogen biosynthesis and metabolism, glycine, serine, alanine, and threonine metabolism, purine metabolism, and tyrosine metabolism were found to map significant metabolites and proteins in understanding the pathology with limited information (Figure S3).

Down-regulation of myeloperoxidase (MPO) in androgen and estrogen biosynthesis and metabolism may have a role in affecting gametocytes. Also, MPO was found to interact indirectly with pyruvate; 4-(2-aminoethyl)-1,2-benzene diol along with fumarate was mapped on the tyrosine metabolism network and was mapped with L-glutamine, urea, and fumarate in purine metabolism. Creatine kinase M-type (CKM) was found to interact indirectly with L-arginine and creatine in glycine, serine, alanine, and threonine metabolism. The mapping of these metabolites and proteins strengthens our metadata analysis by the pathways reported by various research. ${ }^{106}$ This analysis of compiled studies provides a better understanding of the role of inflammation, alteration of IL-6, cytokines, lipids, and amino acids in the progression of the disease. Studies adapted individual or multiomics approaches to understanding the pathobiology of the COVID-19 condition.

\section{CONCLUSIONS}

Since the emergence of the COVID-19 pandemic in December 2019, it has taken one and a half million lives, ${ }^{107}$ and the pandemic has spread across all continents. The planet has the utmost need for a definitive cure and/or efficacious and safe vaccine strategy. Omics-based technologies (genomics, transcriptomics, proteomics, interactomics, and metabolomics) have the potential to provide novel insights into this complex disease.

The COVID-19 pandemic has brought the utility of multiomics research to the forefront to segregate disease pathways rapidly. The use of NGS allowed rapid identification of the pathogen and facilitated the development of RT-PCR assays, as well as research on viral evaluation and infection patterns. Based on cell line studies coupled with MS-based approaches, interactomics of the infectious particle has been carried out rapidly. Such studies have revealed the interactome of viral and host proteins ${ }^{13,72,74,75}$ and produced data on probable therapeutics for disease treatment. ${ }^{13,74}$ These studies reveal the biology of the viral-host and the biochemical pathways it perturbs. Most significant among these are a range of cellular housekeeping functions, such as nucleic acid metabolism, transcription, splicing, translation, protein trafficking, regulation of ubiquitination, inhibition of cell cycle, and others. . $^{3,72,74,75}$ That the viral infection can bring about such an array of changes definitively explains its fatal outcome in severe infection. Host proteome analysis using blood has been instrumental in gauging the response of the host as well as identifying classifiers of severity that will be clinically useful. ${ }^{61,108}$

Several studies on varying grades of severity of COVID-19 have indicated that the disease progression is mediated by commonly dysregulated pathways of innate immune responses, such as complement activation, inflammatory responses, neutrophil activation and degranulation, platelet degranulation, and dysregulation of blood coagulation and metabolism. From these studies, it appears that viral infection induces a strong innate response, as demonstrated by activation of both the classical, alternative pathway complement pathways. ${ }^{39,61,108}$ Further, most COVID-19 patients exhibit up-regulation of the 
inflammation axis. ${ }^{39,47,60,109}$ During the early stages of the disease, it is the cytokine-mediated signaling pathways relating to IL6, IL17, and CCL2 that is dysregulated. ${ }^{60}$ Viral infection produces a strong antiviral interferon response, which precipitates as fever in COVID-19 patients. ${ }^{10}$ This then initiates a chain reaction further up-regulating chemokines, which act as a chemoattractant for migration of leukocytes (e.g., monocytes and neutrophils) from the blood to sites of infection or tissue damage. ${ }^{69,70}$ In fact, studies have shown in the lungs of severe COVID-19 patients there is an infiltration of mononuclear phagocytes and neutrophils, and the usual alveolar macrophages are supplanted by pro-inflammatory monocytederived macrophages. ${ }^{111,112}$ This further induces damage to lung tissue and exacerbates symptoms of COVID-19. Multiple studies have indicated that circulating TNF- $\alpha$ is ominously high in COVID-19 patients ${ }^{47}$ and suggest that this might drive systemic inflammation and result in multiorgan failure in patients.

Blood coagulation pathway disturbance is another hallmark of COVID-19, 99 and this might be precipitated due to excessive inflammation in the lungs as evidenced by increased IL- 6 that in turn promotes vascular permeability and triggers the coagulation cascades leading to vascular thrombosis. Plasma proteome studies have found that acute-phase liver reactants, such as Creactive protein (CRP) and serum amyloid, are upregulated. ${ }^{39,61,108}$ These can serve as clinical biomarkers of severity and may also indicate the onset of hepatic damage due to the liver being exposed to pro-inflammatory molecules via leaky vasculature. Targeting these molecules, as suggested by Shu et al., ${ }^{108}$ could be one of the therapeutic options to manage COVID-19 related complications.

Proteomic analysis of autopsy samples has also revealed that most damages during severe COVID-19 are bought about through the hyperinflammatory milieu coupled with tissue hypoxia that ensues as ARDS. ${ }^{70}$ Major signatures that signify a worsened COVID-19 condition also include alterations in myelomonocytic cell and B-cell composition, significant $\mathrm{T}$ cell phenotype alteration, the elevation of particular cytokine/ chemokines and antibodies specific to SARS-CoV-2. Further, alteration in the levels of IP-10, IL-6, and IL-10 are found to be correlated with disease progression. ${ }^{113}$

On the other hand, viral proteome microarray-based technologies have been instrumental in understanding the immunogenicity of infection. ${ }^{89,92,114,115}$ These also have been instrumental in designing both vaccines and serological tools for virus detection, whereas the protein microarray-based tools, as well as multiplexed immunological panels, have provided unbiased high-throughput analysis on undepleted plasma which MS-based technologies could not achieve. ${ }^{60}$

Metabolites belonging to fatty and amino acid metabolism, ammonia recycling, TCA cycle, guanosine monophosphate (GMP) of nucleotide biosynthesis pathways, and carbamoyl phosphate of urea cycle have also been found to be altered in serum, plasma, and respiratory specimens. These protein and metabolite signatures can provide clues toward finding the most affected and effector molecules or a panel of potential biomarkers that could be extremely selective and sensitive, which, of course, requires much deeper analysis to be performed in the near future. However, the integration of proteomics and metabolomics will help us develop a bigger picture to understand infectious diseases. Hence, a utilitarian method such as MPLEx methodology to extract metabolites, proteins, and lipids from the same sample type as done for MERS CoV also leads to inactivation of the virus due to disintegration of the virus into the three components along with solubility of the biomolecules with the respective solvent system. ${ }^{116}$ Such methods can lead to efficient multiomics studies with the least variation introduced by different sample considerations from different groups.

Omics approaches have also allowed for dissection of the immune response by providing a broad picture of those perturbations occurring after SARS-CoV-2 infection. To summarize, these studies showed that both innate and adaptive immune responses are elicited in reaction to SARS-CoV-2 infection. Moreover, the results exhibited the viruses' ability to inhibit and evade immune response to infection. This may explain why many develop life-threatening complications that arise upon contracting COVID-19. There is increasing evidence that multiple comorbidities, as well as old age and gender, have a bearing on disease outcome. ${ }^{117-119}$ However, molecular mechanisms behind such differences in COVID-19 pathogenesis remain to be elucidated. Longitudinal omics studies on cohorts before and after COVID-19 infection may help understand how the immune memory of disease operates. There is increasing evidence of "long-COVID"; ${ }^{120}$ however, no study yet has examined mechanistic pathways involved that lead to COVID-19 sequelae in a subset of patients. Follow-up studies of those who suffered severe COVID-19 can answer questions regarding long-term sequelae. Many alterations might also be due to the administration of a slew of drugs given the unavailability of precise treatment protocols, so studies especially on animal models, cell lines, and organoid models need to be conducted that further exemplify the mechanistic pathways of disease progression. Additionally, research groups have not just been thinking of repurposing the drugs but also biomolecules. Repurposing of biomolecules includes mesenchymal stromal cell-secreted biomolecules, ${ }^{121}$ which consist of proteins, metabolites, and cytokines, found capable of diminishing the lung-associated diseases. The secretome has properties such as immunomodulatory, pro-angiogenic regenerative, antiprotease, and anti-inflammatory activities which might contribute to a reduction in COVID-19 severity. Gujjar's group $^{122}$ has proposed the possibility of using activated CD $8+\mathrm{T}$ cells from COVID-19 patients as immunotherapy for cancer patients. Hence, the repurposing of drugs and biomolecules might help in understanding and effectively treating disease with minimal side effects.

\section{FUTURE PERSPECTIVES}

The previous century has seen multiple viral/bacterial outbreaks, many of which have evolved into pandemics. Today we live in a world with increasing interdependence among nations and increasing man-wild conflicts. The current pandemic is surely not the last we will face. COVID-19 is perhaps a wake-up call that worse is yet to come. Hence, steps taken today would be beneficial tomorrow. Omics technologies and strategies used to combat the pandemic today might lay the foundations to a longterm blueprint for future outbreaks. Novel breakthroughs achieved through the omics approach will not only aid to combat this pandemic but also propel wider adoption of these technologies by the scientific community, industries, as well as governmental bodies. We reviewed the literature and found that omics technologies have already contributed significantly to our current understanding of COVID-19 pathology (Box 1).

First, it helped in the detection of the infectious agent, which was the first step in understanding the disease. We were able to 
Box 1. COVID-19 OMICS-Based Research Development and Challenges

\section{OMICS-BASED RESEARCH DEVELOPMENT AND} ITS IMPACT

1. Genome of the SARS-CoV-2 mapped by NGS

- RT-PCR assays developed at a rapid pace

- Origins and epidemiology of COVID-19 became easy

- Enabled mass spectrometry to detect viral peptides

2. High-throughput mass spectrometry studies

- Host response understood

- Clinical classifiers of severity

- Drug repurposing studies

3. Protein microarrays

- Plasma studies for biomarkers of severity

- Humoral response against viral proteome

- Epitope mapping and serological tests development

\section{CHALLENGES AND AREAS WHERE IMPACT TO YET BE MADE}

1. COVID-19 data sharing

- Unified SOPs

- Data sharing and meta-analysis

- Multinational cohorts for the better understanding effect of ethnicity

2. Comorbidities

- Effect of pre-existing diseases

- Impact of gender and age on disease

- Impact of comorbidities on the severity

- Drug development for comorbid patients

3. COVID-19 reinfection and immune memory

- Vaccine development

- Vaccination memory

- Multiepitope characterization for vaccination

4. COVID-19 sequelae

- Unraveling biology of "long COVID-19"

- Understanding the long-term effect of COVID-19

- Understanding the fallout of multiorgan injuries on quality of life

map the genome of the infectious agent by NGS, and thus, RTPCR assays could be developed at a rapid pace and deployed around the globe. NGS was used for the sequencing of the SARS-CoV-2 and all variants developed. Around 110,232 sequence runs have been archived for mapping virus alterations across the world. ${ }^{123}$ The spread of the virus across the countries gave rise to NGS results based RT-PCR confirmatory tests for identification of RdRp-IP1, RdRp, upE, ${ }^{124}$ and ORF1ab/N ${ }^{125}$ genes which enabled quick diagnosis of COVID-19 infected patients from the uninfected population starting from a few days to $10 \mathrm{~min}$.

However, to make the process high-throughput, highly sensitive MS-based techniques are also being explored. For example, targeted analysis of structural spike $S$ glycoprotein and replicase polyprotein-1ab peptides, QIAPGQTGK and AIVSTIQRKYK, respectively, are being explored. ${ }^{126}$ MS methodology was further modified to build a paper spray MS for fast and accurate diagnosis within $60 \mathrm{s.}^{127}$ The very recently developed technique SARSeq, an NGS-based testing method, that can perform analysis of up to 36,000 samples in a single run $^{54}$ can resolve the problem of mass testing of COVID-19 at the time of a massive outbreak. Another recently developed in-house metagenomic NGS (mNGS) can detect SARS Cov2 and associated all other pathogens in a clinical sample, which eliminates the necessity of using multiple test kits to detect comorbidity. $^{55}$

Using high-throughput omics scientists also studied the dynamic changes in the metabolome and proteome profile of nonsevere to severe disease cohorts, which could be used to predict the disease development: for example, the simultaneous decline in the levels of malic acid and glycerol 3-phosphate in healthy to mild to fatal groups. ${ }^{80}$ Reduction of malic acid has been linked to hepatic impairment in patients. The level of guanosine monophosphate (GMP) was found to be modulated along with carbamoyl phosphate, CD39, and CD73 in mild to severe patients suggesting the role of immune dysfunction and nucleotide metabolism in the progression of nonsevere COVID19 to severe condition. ${ }^{80}$ Further, the evolving humoral immune signature of the patients has also been being worked out using SARS-CoV-2 microarrays. ${ }^{89,92,114}$

Moreover, studies such as chemoproteomic analysis have helped isolate clinically approved drugs that target host proteins from the virus-host interactome. Studies could identify a total of 29 FDA-approved drugs that showed potent efficacy on viral inactivity in the range of 10 to $100 \mathrm{nM}$, which could be taken forward in clinical trials. Drugs like PB28, zotatifin, and hydroxychloroquine have been shown to exert their antiviral activities during viral replication. ${ }^{13}$

As per the metabolomics analysis of human lung cell lines, it is reported that proteins of the PARP family lead to pathogenesis in COVID-19 by utilizing cellular NAD for its survival and suggested that enhancing the NAD-based defenses can boost innate immunity. ${ }^{128}$ These results might suggest the use of NAM, NAMPT, and NR supplementations as therapeutic alternatives for COVID-19 patients. These results thus open new therapeutic options of drug repurposing as well as biomolecules in treating the diseases based on effector and effected biomolecules.

Other complementary technologies such as the hugely powerful protein microarray have enabled us to map humoral immune response as well as understand proteomics of undepleted plasma. Working on serum protein using an inhouse developed antibody microarray has found proteins to be up-regulated in COVID-19 positive patients belong to a diverse range of host cellular pathways not only combating viral infection (MAPK, ERK1/ERK2, JAK-STAT, PI3K), inflammation, immune cell activation, and migration but also involved in the complement and coagulation process. ${ }^{60}$ The SARS-CoV-2 proteome microarray has shown us the landscape of humoral immune response. In a SARS-CoV-2 proteome microarray covering 18 out of the 28 putative viral proteins, IgG and IgM antibody responses in convalescent patients were studied. ${ }^{89}$ Further, another microarray based on 966 tiled peptides representing the SARS-CoV-2 proteome ${ }^{90}$ reported comparisons of the early stage COVID-19 patients and noninfluenza patient groups describing $76 \mathrm{IgM}$ and $17 \mathrm{IgG}$ antigens that were differentially targeted. Jiang's group ${ }^{129}$ used IgG and IgM antibodies targeting N, S1, ORF9b, and NSP5 proteins of SARSCoV-2 for global profiling of COVID-19. Also, another group reported that the microarray platform-specific to COVID-19 did not show any cross-reactivity with any human proteins but could not differentiate among different clinical manifestations on the 
severity basis. ${ }^{130}$ However, these studies may give high throughput diagnostics, vaccine, and potential therapeutics candidates. ${ }^{129,130}$

Nevertheless, many questions regarding COVID-19 remain to be answered. Omics technologies are capable of answering many. The most confounding factor of COVID-19 is associated with comorbidities. As soon as the pandemic emerged, it was clear that the elderly and comorbid patients were susceptible to severe disease. ${ }^{131}$ Survey-based studies showed a role for diabetes, hypertension, and other major risk factors in severe forms of COVID-19. ${ }^{132}$ However, to date, we have not been able to delineate pathways altered between comorbid severe COVID-19 and noncomorbid severe COVID-19 patients. Such data would do yeoman's service to clinicians at the frontlines of waging war against COVID-19. Most work done to date seems to be designed around available patient cohorts. However, today we need more systematic cohort recruitment and well-defined inclusion-exclusion criteria to understand disease pathogenesis across age groups and comorbidities. The integration of multiomics studies may be used in understanding the synergic relation between these disorders and the COVID19 prognosis mechanism.

While omics technologies have helped us in rapid detection of the infection, however, we have little knowledge of the prognosis of the disease, and this remains challenging (Box 1). Multiple omics approaches have generated classifiers of severity. ${ }^{33,39,59,61}$ The majority of the pathways altered by the SARS-CoV-2 pathogen are generic immune, amino acid, lipid, carbon metabolism, and nucleic acid pathways. ${ }^{77-80,133}$ Targeting these pathways will augment the side effects of the potential drug in the host system. Hence, there is an urgent need for a comprehensive and multiomics integrated understanding of the disease pathology. The knowledge generated needs to be validated across a larger cohort. Further, we need to rule out the markers that were bystander hits of therapeutics that were used in the patient cohort, especially during the earlier part of the pandemic. Large cohorts and unified SOPs can help remove the confounding factors for the discovery of absolute biomarkers of severity of COVID-19 and provide clinical teams with definitive markers.

The next big challenge is the case of COVID-19 reinfection and immune memory. Although vaccines are being developed at an astounding pace, the SARS-CoV-2 genome is simultaneously mutating rapidly. Initiatives such as GISAID are keeping track of this mutational data, ${ }^{134}$ and multiomics technologies can help us understand how the host immune system adapts to altered viral genomes. Reinfections are on the rise and might indicate that complete immunity against SARS-CoV-2 might not be easily attainable. Proteome microarrays and new technologies such as multiplexed in-solution protein microarray (MISPA) can be used to systematically study cohorts segmented according to gender, age, ethnicity, and comorbidities to understand the disease better.

Further, we know little about infections that predispose patients to COVID-19 and secondary infections arising out of COVID-19. There is an urgent need to understand such risk factors. There are studies suggesting severity in COVID-19 patients due to other pathogen coinfections, which may play a crucial role in enhancing a few of the pathways contributing to the severity or prolonging survival in the host system, ${ }^{13 \%, 136}$ suggesting combinatory treatment of the pathogens after detection. A potential panel of $16 \mathrm{~S}$ rRNA along with viral gene targets can be prepared to profile the infections in a patient capable of worsening the COVID-19 manifestation. Crucial questions remain unanswered. An entire spectrum of work remains to be done and understood.

Finally, the long-term challenge would be to understand the long-term sequelae of the disease. If one suffered from COVID19 and then tested negative, can that person be declared healthy. Dennis et al. ${ }^{137}$ did a survey and reported that the patient with low risks has $\geq 1$ organ impairment post-COVID-19 effect. Hence, researchers and clinicians are hypothesizing that COVID-19 not only has high chances to be for a long duration but also is not risk-free for youth with sound immune systems. ${ }^{137,138}$ Long-term persistence of symptoms of COVID-19 is a reality, ${ }^{120}$ and to date, no studies have systematically tried to understand the development of what is now called "long COVID". Multiorgan injuries have been shown in autopsies studies, ${ }^{69,70}$ and this raises concern that survivors may carry many scars of the disease. There is a need for more studies on secondary long-term effects of COVID-19 and how to detect and treat the sequelae. This ongoing work has wideranging medical and social implications across the globe.

Given the diversity in the population studied, sample processing steps, instrumentation used, and data analysis pipeline implemented, it would be unrealistic to conclude the various studies to find biological commonalities and divergence. The differences might well be technical artifacts and/or effects of the population studied. Hence we feel that the time is ripe for an international consortium based work to be carried out with standardized SOPs to find credible and actionable data. In an era where researchers are increasingly using multiomics and computational biology techniques to generate machine learning models to predict the panel of biomolecules that provide prognostic value, the availability of curated data is a major lacunae with very little data available on public platforms. This is required to decode the heterogeneity of the available information. However, much needs to be done so that this pipe dream sees the light of day. Different groups around the world have used multiple protocols and methodologies for assaying different tissue types. Further, research groups use to study specific nomenclatures for disease severity. Moreover, cohorts with variable comorbidities and demographics compound a definitive understanding of disease biology. While it is understandable given the gravity of the situation with the advent of the pandemic, now is perhaps the time to create unified SOPs regarding sample collection and data generation for easy sharing and lucid understanding and analyzing of the data sets. An initiative called the COVID-19 MS Coalition ${ }^{139}$ has begun but needs wider adoption by the scientific community. A widely accessible common platform for sharing curated clinical and omics research data much in the lines of $\mathrm{CPTAC}^{140}$ for cancer and GISAID ${ }^{134}$ for the viral genome will surely help in better understanding of COVID-19 pathogenesis with respect to multiple comorbidities, gender, age, and race and has become a necessity. This can be extended to diseases that have the potential for epidemics as well. With the wealth of curated clinical and research data made available, robust artificial intelligence-based models as per the large data set and information could be developed for the diagnosis and prognosis of COVID-19 patients. Further, data should be made more openly accessible for the clinicians to add their observations, and models may be adapted based on significant and recurring inputs. 


\section{ASSOCIATED CONTENT}

\section{Supporting Information}

The Supporting Information is available free of charge at https://pubs.acs.org/doi/10.1021/acs.jproteome.0c00771.

Gene ontology analysis of the altered proteins in COVID19 positive patients, altered metabolites mapped on altered pathways in SARS-CoV-2 host, inter-mapped significant metabolites and proteins pathways (PDF)

List of altered proteins in COVID-19 positive patients (XLSX)

List of altered metabolites in COVID-19 positive patients (XLSX)

\section{AUTHOR INFORMATION}

\section{Corresponding Author}

Sanjeeva Srivastava - Department of Biosciences and Bioengineering, Indian Institute of Technology Bombay, Mumbai 400076, India; 10 orcid.org/0000-0002-06514438; Phone: +91-22-2576-7779; Email: sanjeeva@ iitb.ac.in; Fax: +91-22-2572-3480

\section{Authors}

Shalini Aggarwal - Department of Biosciences and Bioengineering, Indian Institute of Technology Bombay, Mumbai 400076, India; (1) orcid.org/0000-0002-59512102

Arup Acharjee - Department of Biosciences and Bioengineering, Indian Institute of Technology Bombay, Mumbai 400076, India; (1) orcid.org/0000-0001-5879-215X

Amrita Mukherjee - Department of Biosciences and Bioengineering, Indian Institute of Technology Bombay, Mumbai 400076, India

Mark S. Baker - Department of Biomedical Science, Faculty of Medicine, Health and Human Sciences, Macquarie University, Sydney 2109, Australia; (1) orcid.org/0000-0001-5858-4035

Complete contact information is available at: https://pubs.acs.org/10.1021/acs.jproteome.0c00771

\section{Author Contributions \\ ${ }^{\S}$ S.A. and A.A. contributed equally to this work. \\ Author Contributions}

SS, MB, SA, AA, and AM contributed to conceiving the idea, outline, and writeup. SA did the metadata analysis. SA and AA prepared the figures.

\section{Notes}

The authors declare no competing financial interest.

\section{ACKNOWLEDGMENTS}

The authors would like to acknowledge the Science and Engineering Research Board (SERB), Government of India (SB/S1/Covid-2/2020), and a seed grant (RD/0520IRCCHC0-006) from IRCC, IIT Bombay to SS. SA was supported by the IIT Bombay fellowship, and AM was supported by the UAY-MHRD fellowship. All the figures were created using Servier Medical Art templates, which are licensed under a Creative Commons Attribution 3.0 Unported License; https://smart.servier.com.

\section{REFERENCES}

(1) Wu, F.; Zhao, S.; Yu, B.; Chen, Y.-M.; Wang, W.; Song, Z.-G.; Hu, Y.; Tao, Z.-W.; Tian, J.-H.; Pei, Y.-Y.; Yuan, M.-L.; Zhang, Y.-L.; Dai, F.H.; Liu, Y.; Wang, Q.-M.; Zheng, J.-J.; Xu, L.; Holmes, E. C.; Zhang, Y.Z. A New Coronavirus Associated with Human Respiratory Disease in China. Nature 2020, 579 (7798), 265-269.

(2) Wan, Y.; Shang, J.; Graham, R.; Baric, R. S.; Li, F. Receptor Recognition by the Novel Coronavirus from Wuhan: An Analysis Based on Decade-Long Structural Studies of SARS Coronavirus. J. Virol. 2020, 94 (7), DOI: 10.1128/JVI.00127-20.

(3) Zhang, H.; Penninger, J. M.; Li, Y.; Zhong, N.; Slutsky, A. S. Angiotensin-Converting Enzyme 2 (ACE2) as a SARS-CoV-2 Receptor: Molecular Mechanisms and Potential Therapeutic Target. Intensive Care Med. 2020, 46 (4), 586-590.

(4) Walls, A. C.; Park, Y.-J.; Tortorici, M. A.; Wall, A.; McGuire, A. T.; Veesler, D. Structure, Function, and Antigenicity of the SARS-CoV-2 Spike Glycoprotein. Cell 2020, 181 (2), 281-292 (e6) .

(5) Hadi-Alijanvand, H.; Rouhani, M. Studying the Effects of ACE2 Mutations on the Stability, Dynamics, and Dissociation Process of SARS-CoV-2 S1/HACE2 Complexes. J. Proteome Res. 2020, 19 (11), 4609-4623.

(6) Hoffmann, M.; Kleine-Weber, H.; Schroeder, S.; Krüger, N.; Herrler, T.; Erichsen, S.; Schiergens, T. S.; Herrler, G.; Wu, N.-H.; Nitsche, A.; Müller, M. A.; Drosten, C.; Pöhlmann, S. SARS-CoV-2 Cell Entry Depends on ACE2 and TMPRSS2 and Is Blocked by a Clinically Proven Protease Inhibitor. Cell 2020, 181 (2), 271-280 (e8) .

(7) Li. COVID-19 patients' clinical characteristics, discharge rate, and fatality rate of meta-analysis. Journal of Medical Virology - Wiley Online Library. 2020. https://onlinelibrary.wiley.com/doi/full/10.1002/jmv. 25757 (accessed 2020-09-18).

(8) Huang, C.; Wang, Y.; Li, X.; Ren, L.; Zhao, J.; Hu, Y.; Zhang, L.; Fan, G.; Xu, J.; Gu, X.; Cheng, Z.; Yu, T.; Xia, J.; Wei, Y.; Wu, W.; Xie, X.; Yin, W.; Li, H.; Liu, M.; Xiao, Y.; Gao, H.; Guo, L.; Xie, J.; Wang, G.; Jiang, R.; Gao, Z.; Jin, Q.; Wang, J.; Cao, B. Clinical Features of Patients Infected with 2019 Novel Coronavirus in Wuhan. Lancet 2020, 395 (10223), 497-506.

(9) Zhou, F.; Yu, T.; Du, R.; Fan, G.; Liu, Y.; Liu, Z.; Xiang, J.; Wang, Y.; Song, B.; Gu, X.; Guan, L.; Wei, Y.; Li, H.; Wu, X.; Xu, J.; Tu, S.; Zhang, Y.; Chen, H.; Cao, B. Clinical Course and Risk Factors for Mortality of Adult Inpatients with COVID-19 in Wuhan, China: A Retrospective Cohort Study. Lancet 2020, 395 (10229), 1054-1062.

(10) Wang, D.; Hu, B.; Hu, C.; Zhu, F.; Liu, X.; Zhang, J.; Wang, B.; Xiang, H.; Cheng, Z.; Xiong, Y.; Zhao, Y.; Li, Y.; Wang, X.; Peng, Z. Clinical Characteristics of 138 Hospitalized Patients With 2019 Novel Coronavirus-Infected Pneumonia in Wuhan. China. JAMA 2020, 323 (11), 1061-1069.

(11) Khailany, R. A.; Safdar, M.; Ozaslan, M. Genomic Characterization of a Novel SARS-CoV-2. Gene Reports 2020, 19, 100682.

(12) Wu, A.; Peng, Y.; Huang, B.; Ding, X.; Wang, X.; Niu, P.; Meng, J.; Zhu, Z.; Zhang, Z.; Wang, J.; Sheng, J.; Quan, L.; Xia, Z.; Tan, W.; Cheng, G.; Jiang, T. Genome Composition and Divergence of the Novel Coronavirus (2019-NCoV) Originating in China. Cell Host Microbe 2020, 27 (3), 325-328.

(13) Gordon, D. E.; Jang, G. M.; Bouhaddou, M.; Xu, J.; Obernier, K.; White, K. M.; O'Meara, M. J.; Rezelj, V. V.; Guo, J. Z.; Swaney, D. L.; Tummino, T. A.; Hüttenhain, R.; Kaake, R. M.; Richards, A. L.; Tutuncuoglu, B.; Foussard, H.; Batra, J.; Haas, K.; Modak, M.; Kim, M.; Haas, P.; Polacco, B. J.; Braberg, H.; Fabius, J. M.; Eckhardt, M.; Soucheray, M.; Bennett, M. J.; Cakir, M.; McGregor, M. J.; Li, Q.; Meyer, B.; Roesch, F.; Vallet, T.; Mac Kain, A.; Miorin, L.; Moreno, E.; Naing, Z. Z. C.; Zhou, Y.; Peng, S.; Shi, Y.; Zhang, Z.; Shen, W.; Kirby, I. T.; Melnyk, J. E.; Chorba, J. S.; Lou, K.; Dai, S. A.; Barrio-Hernandez, I.; Memon, D.; Hernandez-Armenta, C.; Lyu, J.; Mathy, C. J. P.; Perica, T.; Pilla, K. B.; Ganesan, S. J.; Saltzberg, D. J.; Rakesh, R.; Liu, X.; Rosenthal, S. B.; Calviello, L.; Venkataramanan, S.; Liboy-Lugo, J.; Lin, Y.; Huang, X.-P.; Liu, Y.; Wankowicz, S. A.; Bohn, M.; Safari, M.; Ugur, F. S.; Koh, C.; Savar, N. S.; Tran, Q. D.; Shengjuler, D.; Fletcher, S. J.; O’Neal, M. C.; Cai, Y.; Chang, J. C. J.; Broadhurst, D. J.; Klippsten, S.; Sharp, P. P.; Wenzell, N. A.; Kuzuoglu-Ozturk, D.; Wang, H.-Y.; 
Trenker, R.; Young, J. M.; Cavero, D. A.; Hiatt, J.; Roth, T. L.; Rathore, U.; Subramanian, A.; Noack, J.; Hubert, M.; Stroud, R. M.; Frankel, A. D.; Rosenberg, O. S.; Verba, K. A.; Agard, D. A.; Ott, M.; Emerman, M.; Jura, N.; von Zastrow, M.; Verdin, E.; Ashworth, A.; Schwartz, O.; d'Enfert, C.; Mukherjee, S.; Jacobson, M.; Malik, H. S.; Fujimori, D. G.; Ideker, T.; Craik, C. S.; Floor, S. N.; Fraser, J. S.; Gross, J. D.; Sali, A.; Roth, B. L.; Ruggero, D.; Taunton, J.; Kortemme, T.; Beltrao, P.; Vignuzzi, M.; García-Sastre, A.; Shokat, K. M.; Shoichet, B. K.; Krogan, N. J. A SARS-CoV-2 Protein Interaction Map Reveals Targets for Drug Repurposing. Nature 2020, 583 (7816), 459-468.

(14) Yoshimoto, F. K. The Proteins of Severe Acute Respiratory Syndrome Coronavirus-2 (SARS CoV-2 or n-COV19), the Cause of COVID-19. Protein J. 2020, 39 (3), 198-216.

(15) Chan, J. F.-W.; Kok, K.-H.; Zhu, Z.; Chu, H.; To, K. K.-W.; Yuan, S.; Yuen, K.-Y. Genomic Characterization of the 2019 Novel HumanPathogenic Coronavirus Isolated from a Patient with Atypical Pneumonia after Visiting Wuhan. Emerging Microbes Infect. 2020, 9 (1), 221-236.

(16) Greco, T. M.; Diner, B. A.; Cristea, I. M. The Impact of Mass Spectrometry-Based Proteomics on Fundamental Discoveries in Virology. Annu. Rev. Virol. 2014, 1 (1), 581-604.

(17) García-Dorival, I.; Wu, W.; Armstrong, S. D.; Barr, J. N.; Carroll, M. W.; Hewson, R.; Hiscox, J. A. Elucidation of the Cellular Interactome of Ebola Virus Nucleoprotein and Identification of Therapeutic Targets. Journal of Proteome Research 2016, 15 (12), 4290-4303.

(18) Scaturro, P.; Kastner, A. L.; Pichlmair, A. Chasing Intracellular Zika Virus Using Proteomics. Viruses 2019, 11 (9), 878.

(19) Puttamallesh, V. N.; Sreenivasamurthy, S. K.; Singh, P. K.; Harsha, H. C.; Ganjiwale, A.; Broor, S.; Pandey, A.; Narayana, J.; Prasad, T. S. K. Proteomic Profiling of Serum Samples from Chikungunya-Infected Patients Provides Insights into Host Response. Clin Proteom 2013, 10 (1), 14.

(20) Chiu, H.-C.; Hannemann, H.; Heesom, K. J.; Matthews, D. A.; Davidson, A. D. High-Throughput Quantitative Proteomic Analysis of Dengue Virus Type 2 Infected A549 Cells. PLoS One 2014, 9 (3), e93305.

(21) Coombs, K. M.; Berard, A.; Xu, W.; Krokhin, O.; Meng, X.; Cortens, J. P.; Kobasa, D.; Wilkins, J.; Brown, E. G. Quantitative Proteomic Analyses of Influenza Virus-Infected Cultured Human Lung Cells. J. Virol. 2010, 84 (20), 10888-10906.

(22) Davies, D. H.; Liang, X.; Hernandez, J. E.; Randall, A.; Hirst, S.; Mu, Y.; Romero, K. M.; Nguyen, T. T.; Kalantari-Dehaghi, M.; Crotty, S.; Baldi, P.; Villarreal, L. P.; Felgner, P. L. Profiling the Humoral Immune Response to Infection by Using Proteome Microarrays: HighThroughput Vaccine and Diagnostic Antigen Discovery. Proc. Natl. Acad. Sci. U. S. A. 2005, 102 (3), 547-552.

(23) Luevano, M.; Bernard, H.-U.; Barrera-Saldaña, H. A.; Trevino, V.; Garcia-Carranca, A.; Villa, L. L.; Monk, B. J.; Tan, X.; Davies, D. H.; Felgner, P. L.; Kalantari, M. High-Throughput Profiling of the Humoral Immune Responses against Thirteen Human Papillomavirus Types by Proteome Microarrays. Virology 2010, 405 (1), 31-40.

(24) Haralambieva, I. H.; Gibson, M. J.; Kennedy, R. B.; Ovsyannikova, I. G.; Warner, N. D.; Grill, D. E.; Poland, G. A. Characterization of Rubella-Specific Humoral Immunity Following Two Doses of MMR Vaccine Using Proteome Microarray Technology. PLoS One 2017, 12 (11), No. e0188149.

(25) Kalantari-Dehaghi, M.; Chun, S.; Chentoufi, A. A.; Pablo, J.; Liang, L.; Dasgupta, G.; Molina, D. M.; Jasinskas, A.; Nakajima-Sasaki, R.; Felgner, J.; Hermanson, G.; BenMohamed, L.; Felgner, P. L.; Davies, D. H. Discovery of Potential Diagnostic and Vaccine Antigens in Herpes Simplex Virus 1 and 2 by Proteome-Wide Antibody Profiling. J. Virol. 2012, 86 (8), 4328-4339.

(26) Mishra, P. M.; Uversky, V. N.; Giri, R. Molecular Recognition Features in Zika Virus Proteome. J. Mol. Biol. 2018, 430 (16), 23722388 .

(27) Kang, D.-W.; Ilhan, Z. E.; Isern, N. G.; Hoyt, D. W.; Howsmon, D. P.; Shaffer, M.; Lozupone, C. A.; Hahn, J.; Adams, J. B.; KrajmalnikBrown, R. Differences in Fecal Microbial Metabolites and Microbiota of
Children with Autism Spectrum Disorders. Anaerobe 2018, 49, 121131.

(28) Rinschen, M. M.; Ivanisevic, J.; Giera, M.; Siuzdak, G. Identification of Bioactive Metabolites Using Activity Metabolomics. Nat. Rev. Mol. Cell Biol. 2019, 20 (6), 353-367.

(29) Wu, L.; Qu, X. Cancer Biomarker Detection: Recent Achievements and Challenges. Chem. Soc. Rev. 2015, 44 (10), 2963-2997.

(30) Weiner, J.; Maertzdorf, J.; Sutherland, J. S.; Duffy, F. J.; Thompson, E.; Suliman, S.; McEwen, G.; Thiel, B.; Parida, S. K.; Zyla, J.; Hanekom, W. A.; Mohney, R. P.; Boom, W. H.; Mayanja-Kizza, H.; Howe, R.; Dockrell, H. M.; Ottenhoff, T. H. M.; Scriba, T. J.; Zak, D. E.; Walzl, G.; Kaufmann, S. H. E. GC6-74 consortium. Metabolite Changes in Blood Predict the Onset of Tuberculosis. Nat. Commun. 2018, 9 (1), 5208.

(31) Pegalajar-Jurado, A.; Fitzgerald, B. L.; Islam, M. N.; Belisle, J. T.; Wormser, G. P.; Waller, K. S.; Ashton, L. V.; Webb, K. J.; Delorey, M. J.; Clark, R. J.; Molins, C. R. Identification of Urine Metabolites as Biomarkers of Early Lyme Disease. Sci. Rep. 2018, 8 (1), 12204.

(32) Bley, H.; Schöbel, A.; Herker, E. Whole Lotta Lipids-From HCV RNA Replication to the Mature Viral Particle. Int. J. Mol. Sci. 2020, 21 (8), 2888.

(33) Song, J.-W.; Lam, S. M.; Fan, X.; Cao, W.-J.; Wang, S.-Y.; Tian, H.; Chua, G. H.; Zhang, C.; Meng, F.-P.; Xu, Z.; Fu, J.-L.; Huang, L.; Xia, P.; Yang, T.; Zhang, S.; Li, B.; Jiang, T.-J.; Wang, R.; Wang, Z.; Shi, M.; Zhang, J.-Y.; Wang, F.-S.; Shui, G. Omics-Driven Systems Interrogation of Metabolic Dysregulation in COVID-19 Pathogenesis. Cell Metab. 2020, 32 (2), 188-202 (e5) .

(34) Chen, N.; Zhou, M.; Dong, X.; Qu, J.; Gong, F.; Han, Y.; Qiu, Y.; Wang, J.; Liu, Y.; Wei, Y.; Xia, J.; Yu, T.; Zhang, X.; Zhang, L. Epidemiological and Clinical Characteristics of 99 Cases of 2019 Novel Coronavirus Pneumonia in Wuhan, China: A Descriptive Study. Lancet 2020, 395 (10223), 507-513.

(35) Heiss, K.; Heidepriem, J.; Fischer, N.; Weber, L. K.; Dahlke, C.; Jaenisch, T.; Loeffler, F. F. Rapid Response to Pandemic Threats: Immunogenic Epitope Detection of Pandemic Pathogens for Diagnostics and Vaccine Development Using Peptide Microarrays. J. Proteome Res. 2020, 19 (11), 4339-4354.

(36) Nalbantoglu, S. Metabolomics: Basic Principles and Strategies. Mol. Med. 2019, DOI: 10.5772/intechopen.88563.

(37) Franklin, S.; Vondriska, T. M. Genomes, Proteomes, and the Central Dogma. Circ.: Cardiovasc. Genet. 2011, 4 (5), 576.

(38) Nägele, T. Linking Metabolomics Data to Underlying Metabolic Regulation. Front Mol Biosci 2014, 1, 22.

(39) Shen, B.; Yi, X.; Sun, Y.; Bi, X.; Du, J.; Zhang, C.; Quan, S.; Zhang, F.; Sun, R.; Qian, L. Proteomic and Metabolomic Characterization of COVID-19 Patient Sera. Cell 2020, 182 (1), 59-72.

(40) Ribbenstedt, A.; Ziarrusta, H.; Benskin, J. P. Development, Characterization and Comparisons of Targeted and Non-Targeted Metabolomics Methods. PLoS One 2018, 13 (11), No. e0207082.

(41) Schymanski, E. L.; Jeon, J.; Gulde, R.; Fenner, K.; Ruff, M.; Singer, H. P.; Hollender, J. Identifying Small Molecules via High Resolution Mass Spectrometry: Communicating Confidence. Environ. Sci. Technol. 2014, 48 (4), 2097-2098.

(42) Raj, V. S.; Lamers, M. M.; Smits, S. L.; Demmers, J. A. A.; Mou, H.; Bosch, B.-J.; Haagmans, B. L. Identification of Protein Receptors for Coronaviruses by Mass Spectrometry. In Coronaviruses: Methods and Protocols; Maier, H. J., Bickerton, E., Britton, P., Eds.; Methods in Molecular Biology; Springer: New York, NY, 2015; pp 165-182. DOI: $10.1007 / 978-1-4939-2438-7 \quad 15$.

(43) Chen, Y.; Huang, A.; Ao, W.; Wang, Z.; Yuan, J.; Song, Q.; Wei, D.; Ye, H. Proteomic Analysis of Serum Proteins from HIV/AIDS Patients with Talaromyces Marneffei Infection by TMT LabelingBased Quantitative Proteomics. Clin. Proteomics 2018, 15 (1), 40.

(44) Moor, K.; Terada, Y.; Taketani, A.; Matsuyoshi, H.; Ohtani, K. Early Detection of Virus Infection in Live Human Cells Using Raman Spectroscopy. J. Biomed. Opt. 2018, 23 (9), No. 097001.

(45) Saleem, M.; Ali, S.; Khan, M. B.; Amin, A.; Bilal, M.; Nawaz, H.; Hassan, M. Optical Diagnosis of Hepatitis B Virus Infection in Blood 
Plasma Using Raman Spectroscopy and Chemometric Techniques. J. Raman Spectrosc. 2020, 51 (7), 1067-1077.

(46) Desai, S.; Mishra, S. V.; Joshi, A.; Sarkar, D.; Hole, A.; Mishra, R.; Dutt, S.; Chilakapati, M. K.; Gupta, S.; Dutt, A. Raman SpectroscopyBased Detection of RNA Viruses in Saliva: A Preliminary Report. J. Biophotonics 202013 (10), e202000189.

(47) Hadjadj, J.; Yatim, N.; Barnabei, L.; Corneau, A.; Boussier, J.; Smith, N.; Péré, H.; Charbit, B.; Bondet, V.; Chenevier-Gobeaux, C.; Breillat, P.; Carlier, N.; Gauzit, R.; Morbieu, C.; Pène, F.; Marin, N.; Roche, N.; Szwebel, T.-A.; Merkling, S. H.; Treluyer, J.-M.; Veyer, D.; Mouthon, L.; Blanc, C.; Tharaux, P.-L.; Rozenberg, F.; Fischer, A.; Duffy, D.; Rieux-Laucat, F.; Kernéis, S.; Terrier, B. Impaired Type I Interferon Activity and Inflammatory Responses in Severe COVID-19 Patients. Science 2020, 369 (6504), 718-724.

(48) Wu, H.; Larsen, C. P.; Hernandez-Arroyo, C. F.; Mohamed, M. M. B.; Caza, T.; Sharshir, M.; Chughtai, A.; Xie, L.; Gimenez, J. M.; Sandow, T. A.; Lusco, M. A.; Yang, H.; Acheampong, E.; Rosales, I. A.; Colvin, R. B.; Fogo, A. B.; Velez, J. C. Q. AKI and Collapsing Glomerulopathy Associated with COVID-19 and APOL 1 High-Risk Genotype. J. Am. Soc. Nephrol. 2020, 31 (8), 1688-1695.

(49) Trouillet-Assant, S.; Viel, S.; Gaymard, A.; Pons, S.; Richard, J.C.; Perret, M.; Villard, M.; Brengel-Pesce, K.; Lina, B.; Mezidi, M.; Bitker, L.; Belot, A.; Group, C. H. S. Type I IFN Immunoprofiling in COVID-19 Patients. J. Allergy Clin. Immunol. 2020, 146 (1), 206.

(50) Zhou, P.; Yang, X.-L.; Wang, X.-G.; Hu, B.; Zhang, L.; Zhang, W.; Si, H.-R.; Zhu, Y.; Li, B.; Huang, C.-L.; Chen, H.-D.; Chen, J.; Luo, Y.; Guo, H.; Jiang, R.-D.; Liu, M.-Q.; Chen, Y.; Shen, X.-R.; Wang, X.; Zheng, X.-S.; Zhao, K.; Chen, Q.-J.; Deng, F.; Liu, L.-L.; Yan, B.; Zhan, F.-X.; Wang, Y.-Y.; Xiao, G.-F.; Shi, Z.-L. A Pneumonia Outbreak Associated with a New Coronavirus of Probable Bat Origin. Nature 2020, 579 (7798), 270-273.

(51) Corman, V. M.; Landt, O.; Kaiser, M.; Molenkamp, R.; Meijer, A.; Chu, D. K.; Bleicker, T.; Brünink, S.; Schneider, J.; Schmidt, M. L.; Mulders, D. G.; Haagmans, B. L.; van der Veer, B.; van den Brink, S.; Wijsman, L.; Goderski, G.; Romette, J.-L.; Ellis, J.; Zambon, M.; Peiris, M.; Goossens, H.; Reusken, C.; Koopmans, M. P.; Drosten, C. Detection of 2019 Novel Coronavirus (2019-NCoV) by Real-Time RT-PCR. Eurosurveillance 2020, 25 (3), 2000045.

(52) Korber, B.; Fischer, W. M.; Gnanakaran, S.; Yoon, H.; Theiler, J.; Abfalterer, W.; Hengartner, N.; Giorgi, E. E.; Bhattacharya, T.; Foley, B.; Hastie, K. M.; Parker, M. D.; Partridge, D. G.; Evans, C. M.; Freeman, T. M.; de Silva, T. I.; Angyal, A.; Brown, R. L.; Carrilero, L.; Green, L. R.; Groves, D. C.; Johnson, K. J.; Keeley, A. J.; Lindsey, B. B.; Parsons, P. J.; Raza, M.; Rowland-Jones, S.; Smith, N.; Tucker, R. M.; Wang, D.; Wyles, M. D.; McDanal, C.; Perez, L. G.; Tang, H.; MoonWalker, A.; Whelan, S. P.; LaBranche, C. C.; Saphire, E. O.; Montefiori, D. C. Tracking Changes in SARS-CoV-2 Spike: Evidence That D614G Increases Infectivity of the COVID-19 Virus. Cell 2020, 182 (4), 812827 (e19) .

(53) Gonzalez-Reiche, A. S.; Hernandez, M. M.; Sullivan, M. J.; Ciferri, B.; Alshammary, H.; Obla, A.; Fabre, S.; Kleiner, G.; Polanco, J.; Khan, Z.; Alburquerque, B.; Guchte, A. van de; Dutta, J.; Francoeur, N.; Melo, B. S.; Oussenko, I.; Deikus, G.; Soto, J.; Sridhar, S. H.; Wang, Y.C.; Twyman, K.; Kasarskis, A.; Altman, D. R.; Smith, M.; Sebra, R.; Aberg, J.; Krammer, F.; García-Sastre, A.; Luksza, M.; Patel, G.; PanizMondolfi, A.; Gitman, M.; Sordillo, E. M.; Simon, V.; Bakel, H. van. Introductions and Early Spread of SARS-CoV-2 in the New York City Area. Science 2020, 369 (6501), 297-301.

(54) Yelagandula, R.; Bykov, A.; Vogt, A.; Heinen, R.; Özkan, E.; Strobl, M. M.; Baar, J. C.; Uzunova, K.; Hajdusits, B.; Kordic, D.; Suljic, E.; Kurtovic-Kozaric, A.; Izetbegovic, S.; Schaefer, J.; Hufnagl, P.; Zoufaly, A.; Seitz, T.; VCDI; Födinger, M.; Allerberger, F.; Stark, A.; Cochella, L.; Elling, U. SARSeq, a Robust and Highly Multiplexed NGS Assay for Parallel Detection of SARS-CoV2 and Other Respiratory Infections. medRxiv 2020, DOI: 10.1101/2020.10.28.20217778.

(55) Charre, C.; Ginevra, C.; Sabatier, M.; Regue, H.; Destras, G.; Brun, S.; Burfin, G.; Scholtes, C.; Morfin, F.; Valette, M.; Lina, B.; Bal, A.; Josset, L. Evaluation of NGS-Based Approaches for SARS-CoV-2
Whole Genome Characterisation. Virus Evol. 2020, 6, DOI: 10.1093/ ve/veaa075.

(56) Mostafa, H. H.; Fissel, J. A.; Fanelli, B.; Bergman, Y.; Gniazdowski, V.; Dadlani, M.; Carroll, K. C.; Colwell, R. R.; Simner, P. J. Metagenomic Next-Generation Sequencing of Nasopharyngeal Specimens Collected from Confirmed and Suspect COVID-19 Patients. mBio 2020, 11 (6), DOI: 10.1128/mBio.01969-20.

(57) Schultheiß, C.; Paschold, L.; Simnica, D.; Mohme, M.; Willscher, E.; von Wenserski, L.; Scholz, R.; Wieters, I.; Dahlke, C.; Tolosa, E.; Sedding, D. G.; Ciesek, S.; Addo, M.; Binder, M. Next-Generation Sequencing of $\mathrm{T}$ and B Cell Receptor Repertoires from COVID-19 Patients Showed Signatures Associated with Severity of Disease. Immunity 2020, 53 (2), 442-455 (e4).

(58) Patel, H.; Ashton, N. J.; Dobson, R. J.; Anderson, L.; Yilmaz, A.; Blennow, K.; Gisslen, M.; Zetterberg, H. Proteomic Blood Profiling in Mild, Severe and Critical COVID-19 Patients. medRxiv 2020.

(59) D’Alessandro, A.; Thomas, T.; Dzieciatkowska, M.; Hill, R. C.; Francis, R. O.; Hudson, K. E.; Zimring, J. C.; Hod, E. A.; Spitalnik, S. L.; Hansen, K. C. Serum Proteomics in COVID-19 Patients: Altered Coagulation and Complement Status as a Function of IL-6 Level. J. Proteome Res. 2020, 19, 4417.

(60) Hou, X.; Zhang, X.; Wu, X.; Lu, M.; Wang, D.; Xu, M.; Wang, H.; Dai, J.; Duan, H.; Xu, Y.; Yu, X.; Li, Y. Serum Protein Profiling Reveals a Landscape of Inflammation and Immune Signaling in Early-Stage COVID-19 Infection. medRxiv 2020, DOI: 10.1101/ 2020.05.08.20095836.

(61) Messner, C. B.; Demichev, V.; Wendisch, D.; Michalick, L.; White, M.; Freiwald, A.; Textoris-Taube, K.; Vernardis, S. I.; Egger, A.S.; Kreidl, M. Ultra-High-Throughput Clinical Proteomics Reveals Classifiers of COVID-19 Infection. Cell Systems 2020, 11 (1), 11-24.

(62) Liang, Q.; Li, J.; Guo, M.; Tian, X.; Liu, C.; Wang, X.; Yang, X.; Wu, P.; Xiao, Z.; Qu, Y. Virus-Host Interactome and Proteomic Survey of PMBCs from COVID-19 Patients Reveal Potential Virulence Factors Influencing SARS-CoV-2 Pathogenesis. bioRxiv 2020.

(63) Akgun, E.; Tuzuner, M. B.; Sahin, B.; Kilercik, M.; Kulah, C.; Cakiroglu, H. N.; Serteser, M.; Unsal, I.; Baykal, A. T. Proteins Associated with Neutrophil Degranulation Are Upregulated in Nasopharyngeal Swabs from SARS-CoV-2 Patients. PLoS One 2020, 15 (10), DOI: 10.1371/journal.pone.0240012.

(64) Camp, J. V.; Jonsson, C. B. A Role for Neutrophils in Viral Respiratory Disease. Front. Immunol. 2017, 8, 550.

(65) Rivera, B.; Leyva, A.; Portela, M. M.; Moratorio, G.; Moreno, P.; Durán, R.; Lima, A. Quantitative Proteomic Dataset from Oro- and Naso-Pharyngeal Swabs Used for COVID-19 Diagnosis: Detection of Viral Proteins and Host's Biological Processes Altered by the Infection. Data in Brief 2020, 32, 106121.

(66) Honkala, A. T.; Tailor, D.; Malhotra, S. V. Guanylate-Binding Protein 1: An Emerging Target in Inflammation and Cancer. Front. Immunol. 2020, 10, DOI: 10.3389/fimmu.2019.03139.

(67) Ihling, C.; Tänzler, D.; Hagemann, S.; Kehlen, A.; Hüttelmaier, S.; Sinz, A. Mass Spectrometric Identification of SARS-CoV-2 Proteins from Gargle Solution Samples of COVID-19 Patients. preprint; 2020, DOI: $10.1101 / 2020.04 .18 .047878$.

(68) Wu, M.; Chen, Y.; Xia, H.; Wang, C.; Tan, C. Y.; Cai, X.; Liu, Y.; Ji, F.; Xiong, P.; Liu, R.; Guan, Y.; Duan, Y.; Kuang, D.; Xu, S.; Cai, H.; Xia, Q.; Yang, D.; Wang, M.-W.; Chiu, I. M.; Cheng, C.; Ahern, P. P.; Liu, L.; Wang, G.; Surana, N. K.; Xia, T.; Kasper, D. L. Transcriptional and Proteomic Insights into the Host Response in Fatal COVID-19 Cases. Proc. Natl. Acad. Sci. U. S. A. 2020, 117, 28336.

(69) Qiu, Y.; Wu, D.; Ning, W.; Zhang, J.; Shu, T.; Huang, C.; Chen, R.; Huang, M.; Xu, J.; Yang, Q.; Li, R.; Bie, Y.; Yang, X.; Mu, J.; Wang, Y.; Han, Y.; Zou, X.; Ren, Y.; Pan, S.; Zhang, D.-Y.; Xue, Y.; Shang, Y.; Zhou, X. Postmortem Tissue Proteomics Reveals the Pathogenesis of Multiorgan Injuries of COVID-19. preprint; In Review, 2020, DOI: $10.21203 /$ rs.3.rs-38091/v1.

(70) Nie, X.; Qian, L.; Sun, R.; Huang, B.; Dong, X.; Xiao, Q.; Zhang, Q.; Lu, T.; Yue, L.; Chen, S. Multi-Organ Proteomic Landscape of COVID-19 Autopsies. medRxiv 2020. 
(71) Li, Y.; Wang, Y.; Liu, H.; Sun, W.; Ding, B.; Zhao, Y.; Chen, P.; Zhu, L.; Li, Z.; Li, N.; Chang, L.; Wang, H.; Bai, C.; Xu, P. Urine Proteome of COVID-19 Patients. preprint; Infectious Diseases (except HIV/AIDS) 2020, DOI: 10.1101/2020.05.02.20088666.

(72) Bojkova, D.; Klann, K.; Koch, B.; Widera, M.; Krause, D.; Ciesek, S.; Cinatl, J.; Münch, C. Proteomics of SARS-CoV-2-Infected Host Cells Reveals Therapy Targets. Nature 2020, 583 (7816), 469-472.

(73) Gordon et al._2020_A SARS-CoV-2 Protein Interaction Map Reveals Targets for Drug Repurposing.Pdf.

(74) Bouhaddou, M.; Memon, D.; Meyer, B.; White, K. M.; Rezelj, V. V.; Correa Marrero, M.; Polacco, B. J.; Melnyk, J. E.; Ulferts, S.; Kaake, R. M.; Batra, J.; Richards, A. L.; Stevenson, E.; Gordon, D. E.; Rojc, A.; Obernier, K.; Fabius, J. M.; Soucheray, M.; Miorin, L.; Moreno, E.; Koh, C.; Tran, Q. D.; Hardy, A.; Robinot, R.; Vallet, T.; Nilsson-Payant, B. E.; Hernandez-Armenta, C.; Dunham, A.; Weigang, S.; Knerr, J.; Modak, M.; Quintero, D.; Zhou, Y.; Dugourd, A.; Valdeolivas, A.; Patil, T.; Li, Q.; Hüttenhain, R.; Cakir, M.; Muralidharan, M.; Kim, M.; Jang, G.; Tutuncuoglu, B.; Hiatt, J.; Guo, J. Z.; Xu, J.; Bouhaddou, S.; Mathy, C. J. P.; Gaulton, A.; Manners, E. J.; Félix, E.; Shi, Y.; Goff, M.; Lim, J. K.; McBride, T.; O’Neal, M. C.; Cai, Y.; Chang, J. C. J.; Broadhurst, D. J.; Klippsten, S.; De wit, E.; Leach, A. R.; Kortemme, T.; Shoichet, B.; Ott, M.; Saez-Rodriguez, J.; tenOever, B. R.; Mullins, R. D.; Fischer, E. R.; Kochs, G.; Grosse, R.; García-Sastre, A.; Vignuzzi, M.; Johnson, J. R.; Shokat, K. M.; Swaney, D. L.; Beltrao, P.; Krogan, N. J. The Global Phosphorylation Landscape of SARS-CoV-2 Infection. Cell 2020, 182 (3), 685-712 (e19) .

(75) Li, J.; Guo, M.; Tian, X.; Wang, X.; Yang, X.; Wu, P.; Liu, C.; Xiao, Z.; Qu, Y.; Yin, Y.; Wang, C.; Zhang, Y.; Zhu, Z.; Liu, Z.; Peng, C.; Zhu, T.; Liang, Q. Virus-Host Interactome and Proteomic Survey Reveal Potential Virulence Factors Influencing SARS-CoV-2 Pathogenesis. Med 2020, DOI: 10.1016/j.medj.2020.07.002.

(76) Kolaczkowska, E.; Kubes, P. Neutrophil Recruitment and Function in Health and Inflammation. Nat. Rev. Immunol. 2013, 13 (3), 159-175.

(77) Shen, B.; Yi, X.; Sun, Y.; Bi, X.; Du, J.; Zhang, C.; Quan, S.; Zhang, F.; Sun, R.; Qian, L.; Ge, W.; Liu, W.; Liang, S.; Chen, H.; Zhang, Y.; Li, J.; Xu, J.; He, Z.; Chen, B.; Wang, J.; Yan, H.; Zheng, Y.; Wang, D.; Zhu, J.; Kong, Z.; Kang, Z.; Liang, X.; Ding, X.; Ruan, G.; Xiang, N.; Cai, X.; Gao, H.; Li, L.; Li, S.; Xiao, Q.; Lu, T.; Zhu, Y.; Liu, H.; Chen, H.; Guo, T. Proteomic and Metabolomic Characterization of COVID-19 Patient Sera. Cell 2020, 182 (1), 59-72 (e15) .

(78) Song, J.-W.; Lam, S. M.; Fan, X.; Cao, W.-J.; Wang, S.-Y.; Tian, H.; Chua, G. H.; Zhang, C.; Meng, F.-P.; Xu, Z.; Fu, J.-L.; Huang, L.; Xia, P.; Yang, T.; Zhang, S.; Li, B.; Jiang, T.-J.; Wang, R.; Wang, Z.; Shi, M.; Zhang, J.-Y.; Wang, F.-S.; Shui, G. Omics-Driven Systems Interrogation of Metabolic Dysregulation in COVID-19 Pathogenesis. Cell Metab. 2020, 32 (2), 188-202 (e5) .

(79) Thomas, T.; Stefanoni, D.; Reisz, J. A.; Nemkov, T.; Bertolone, L.; Francis, R. O.; Hudson, K. E.; Zimring, J. C.; Hansen, K. C.; Hod, E. A.; Spitalnik, S. L.; D'Alessandro, A. COVID-19 infection alters kynurenine and fatty acid metabolism, correlating with IL-6 levels and renal status. https://insight.jci.org/articles/view/140327/pdf (accessed 2020-09-07). DOI: 10.1172/jci.insight.140327.

(80) Wu, D.; Shu, T.; Yang, X.; Song, J.-X.; Zhang, M.; Yao, C.; Liu, W.; Huang, M.; Yu, Y.; Yang, Q.; Zhu, T.; Xu, J.; Mu, J.; Wang, Y.; Wang, H.; Tang, T.; Ren, Y.; Wu, Y.; Lin, S.-H.; Qiu, Y.; Zhang, D.-Y.; Shang, Y.; Zhou, X. Plasma Metabolomic and Lipidomic Alterations Associated with COVID-19. Natl Sci Rev 2020, 7 (7), 1157-1168.

(81) Thomas, T.; Stefanoni, D.; Reisz, J. A.; Nemkov, T.; Bertolone, L.; Francis, R. O.; Hudson, K. E.; Zimring, J. C.; Hansen, K. C.; Hod, E. A.; Spitalnik, S. L.; D'Alessandro, A. COVID-19 infection alters kynurenine and fatty acid metabolism, correlating with IL-6 levels and renal status. https://insight.jci.org/articles/view/140327/pdf (accessed 2020-09-07). DOI: 10.1172/jci.insight.140327.

(82) Wu, D.; Shu, T.; Yang, X.; Song, J.-X.; Zhang, M.; Yao, C.; Liu, W.; Huang, M.; Yu, Y.; Yang, Q.; Zhu, T.; Xu, J.; Mu, J.; Wang, Y.; Wang, H.; Tang, T.; Ren, Y.; Wu, Y.; Lin, S.-H.; Qiu, Y.; Zhang, D.-Y.; Shang, Y.; Zhou, X. Plasma Metabolomic and Lipidomic Alterations Associated with COVID-19. Natl Sci Rev 2020, 7 (7), 1157-1168.
(83) Maras, J. S.; Sharma, S.; Bhat, A. R.; Aggarwal, R.; Gupta, E.; Sarin, S. K. Multi-Omics Integration Analysis of Respiratory Specimen Characterizes Baseline Molecular Determinants Associated with COVID-19 Diagnosis. medRxiv 2020, DOI: 10.1101/ 2020.07.06.20147082.

(84) Minhas, P. S.; Liu, L.; Moon, P. K.; Joshi, A. U.; Dove, C.; Mhatre, S.; Contrepois, K.; Wang, Q.; Lee, B. A.; Coronado, M.; Bernstein, D.; Snyder, M. P.; Migaud, M.; Majeti, R.; Mochly-Rosen, D.; Rabinowitz, J. D.; Andreasson, K. I. Macrophage de Novo NAD+ Synthesis Specifies Immune Function in Aging and Inflammation. Nat. Immunol. 2019, 20 (1), 50-63.

(85) Cameron, A. M.; Castoldi, A.; Sanin, D. E.; Flachsmann, L. J.; Field, C. S.; Puleston, D. J.; Kyle, R. L.; Patterson, A. E.; Hässler, F.; Buescher, J. M.; Kelly, B.; Pearce, E. L.; Pearce, E. J. Inflammatory Macrophage Dependence on NAD + Salvage Is a Consequence of Reactive Oxygen Species-Mediated DNA Damage. Nat. Immunol. 2019, 20 (4), 420-432.

(86) Heer, C. D.; Sanderson, D. J.; Voth, L. S.; Alhammad, Y. M. O.; Schmidt, M. S.; Trammell, S. A. J.; Perlman, S.; Cohen, M. S.; Fehr, A. R.; Brenner, C. Coronavirus Infection and PARP Expression Dysregulate the NAD Metabolome: An Actionable Component of Innate Immunity. J. Biol. Chem. 2020, 295, 17986.

(87) Jiang, H.; Zhang, H.; Meng, Q.; Xie, J.; Li, Y.; Chen, H.; Zheng, Y.; Wang, X.; Qi, H.; Zhang, J.; Wang, P.-H.; Han, Z.-G.; Tao, S. SARSCoV-2 Orf9b Suppresses Type I Interferon Responses by Targeting TOM70. Cell. Mol. Immunol. 2020, 17 (9), 998-1000.

(88) Stukalov, A.; Girault, V.; Grass, V.; Bergant, V.; Karayel, O.; Urban, C.; Haas, D. A.; Huang, Y.; Oubraham, L.; Wang, A. Multi-Level Proteomics Reveals Host-Perturbation Strategies of SARS-CoV-2 and SARS-CoV. Biorxiv 2020.

(89) Jiang, H.; Li, Y.; Zhang, H.; Wang, W.; Men, D.; Yang, X.; Qi, H.; Zhou, J.; Tao, S. Global Profiling of SARS-CoV-2 Specific IgG/IgM Responses of Convalescents Using a Proteome Microarray. medRxiv 2020.

(90) Zhang, X.; Wu, X.; Wang, D.; Lu, M.; Hou, X.; Wang, H.; Liang, T.; Dai, J.; Duan, H.; Xu, Y. Proteome-Wide Analysis of DifferentiallyExpressed SARS-CoV-2 Antibodies in Early COVID-19 Infection. medRxiv 2020.

(91) Dahlke, C.; Heidepriem, J.; Kobbe, R.; Santer, R.; Koch, T.; Fathi, A.; Ly, M. L.; Schmiedel, S.; Seeberger, P. H.; Addo, M. M. Distinct Early IgA Profile May Determine Severity of COVID-19 Symptoms: An Immunological Case Series. medRxiv 2020.

(92) de Assis, R. R.; Jain, A.; Nakajima, R.; Jasinskas, A.; Felgner, J.; Obiero, J. M.; Adenaiye, O.; Tai, S.; Hong, F.; Norris, P. J.; Stone, M.; Simmons, G.; Bagri, A.; Schreiber, M.; Buser, A.; Holbro, A.; Battegay, M.; Hosimer, P.; Noesen, C.; Milton, D. K.; Davies, D. H.; Contestable, P.; Corash, L. M.; Busch, M. P.; Felgner, P. L.; Khan, S. Analysis of SARS-CoV-2 Antibodies in COVID-19 Convalescent Blood Using a Coronavirus Antigen Microarray. bioRxiv 2020. DOI: 10.1101/ 2020.04.15.043364.

(93) Chong. Using MetaboAnalyst 4.0 for Comprehensive and Integrative Metabolomics Data Analysis. Current Protocols in Bioinformatics - Wiley Online Library. 2019 https://currentprotocols. onlinelibrary.wiley.com/doi/abs/10.1002/cpbi.86 (accessed 2020-09$18)$.

(94) NetworkAnalyst for statistical, visual and network-based metaanalysis of gene expression data. Nature Protocols https://www.nature. com/articles/nprot.2015.052 (accessed 2020-09-18).

(95) Xia, J.; Lyle, N. H.; Mayer, M. L.; Pena, O. M.; Hancock, R. E. W. INVEX - a Web-Based Tool for Integrative Visualization of Expression Data. Bioinformatics 2013, 29 (24), 3232-3234.

(96) Xia, J.; Benner, M. J.; Hancock, R. E. W. NetworkAnalyst Integrative Approaches for Protein-Protein Interaction Network Analysis and Visual Exploration. Nucleic Acids Res. 2014, 42 (W1), W167-W174.

(97) Wilke, C. O. Bringing Molecules Back into Molecular Evolution. PLoS Comput. Biol. 2012, 8 (6), e1002572.

(98) W, H. da; Bt, S.; Ra, L. Systematic and integrative analysis of large gene lists using DAVID bioinformatics resources. https://pubmed. 
ncbi.nlm.nih.gov/19131956/?dopt=Abstract（accessed 2020-09-18). DOI: $10.1038 /$ nprot.2008.211.

(99) Sidiropoulos, K.; Viteri, G.; Sevilla, C.; Jupe, S.; Webber, M.; Orlic-Milacic, M.; Jassal, B.; May, B.; Shamovsky, V.; Duenas, C.; Rothfels, K.; Matthews, L.; Song, H.; Stein, L.; Haw, R.; D’Eustachio, P.; Ping, P.; Hermjakob, H.; Fabregat, A. Reactome Enhanced Pathway Visualization. Bioinformatics 2017, 33 (21), 3461-3467.

(100) Pang, Z.; Chong, J.; Li, S.; Xia, J. MetaboAnalystR 3.0: Toward an Optimized Workflow for Global Metabolomics. Metabolites 2020, 10 (5), 186.

(101) Mi, H.; Muruganujan, A.; Thomas, P. D. PANTHER in 2013: Modeling the Evolution of Gene Function, and Other Gene Attributes, in the Context of Phylogenetic Trees. Nucleic Acids Res. 2013, 41 (Database issue), D377-386.

(102) Kanehisa, M.; Sato, Y. KEGG Mapper for Inferring Cellular Functions from Protein Sequences. Protein Sci. 2020, 29 (1), 28-35.

(103) Jassal, B.; Matthews, L.; Viteri, G.; Gong, C.; Lorente, P.; Fabregat, A.; Sidiropoulos, K.; Cook, J.; Gillespie, M.; Haw, R.; Loney, F.; May, B.; Milacic, M.; Rothfels, K.; Sevilla, C.; Shamovsky, V.; Shorser, S.; Varusai, T.; Weiser, J.; Wu, G.; Stein, L.; Hermjakob, H.; D'Eustachio, P. The Reactome Pathway Knowledgebase. Nucleic Acids Res. 2019, 48 (D1), D498-D503.

(104) Huang, D. W.; Sherman, B. T.; Lempicki, R. A. Bioinformatics Enrichment Tools: Paths toward the Comprehensive Functional Analysis of Large Gene Lists. Nucleic Acids Res. 2009, 37 (1), 1-13.

(105) Heer, C. D.; Sanderson, D. J.; Voth, L. S.; Alhammad, Y. M. O.; Schmidt, M. S.; Trammell, S. A. J.; Perlman, S.; Cohen, M. S.; Fehr, A. R.; Brenner, C. Coronavirus Infection and PARP Expression Dysregulate the NAD Metabolome: An Actionable Component of Innate Immunity. bioRxiv 2020, DOI: 10.1101/2020.04.17.047480.

(106) Mjaess, G.; Karam, A.; Aoun, F.; Albisinni, S.; Roumeguère, T. COVID-19 and the Male Susceptibility: The Role of ACE2, TMPRSS2 and the Androgen Receptor. Prog Urol 2020, 30 (10), 484-487.

(107) Coronavirus COVID-19 global cases by Center for Systems Science and Engineering (CSSE) at Johns Hopkins University 2020 [Available from: https://coronavirus. jhu. edu/map. html https:// coronavirus. jhu. edu/map. html].

(108) Shu, T.; Ning, W.; Wu, D.; Xu, J.; Han, Q.; Huang, M.; Zou, X.; Yang, Q.; Yuan, Y.; Bie, Y.; Pan, S.; Mu, J.; Han, Y.; Yang, X.; Zhou, H.; Li, R.; Ren, Y.; Chen, X.; Yao, S.; Qiu, Y.; Zhang, D.-Y.; Xue, Y.; Shang, Y.; Zhou, X. Plasma Proteomics Identify Biomarkers and Pathogenesis of COVID-19. Immunity 2020, 53, 1108.

(109) Bock, J.-O.; Ortea, I. Re-Analysis of SARS-CoV-2-Infected Host Cell Proteomics Time-Course Data by Impact Pathway Analysis and Network Analysis: A Potential Link with Inflammatory Response. Aging 2020, 12 (12), 11277-11286.

(110) Merad, M.; Martin, J. C. Pathological Inflammation in Patients with COVID-19: A Key Role for Monocytes and Macrophages. Nat. Rev. Immunol. 2020, 20 (6), 355-362.

(111) Chua, R. L.; Lukassen, S.; Trump, S.; Hennig, B. P.; Wendisch, D.; Pott, F.; Debnath, O.; Thürmann, L.; Kurth, F.; Völker, M. T.; Kazmierski, J.; Timmermann, B.; Twardziok, S.; Schneider, S.; Machleidt, F.; Müller-Redetzky, H.; Maier, M.; Krannich, A.; Schmidt, S.; Balzer, F.; Liebig, J.; Loske, J.; Suttorp, N.; Eils, J.; Ishaque, N.; Liebert, U. G.; von Kalle, C.; Hocke, A.; Witzenrath, M.; Goffinet, C.; Drosten, C.; Laudi, S.; Lehmann, I.; Conrad, C.; Sander, L.-E.; Eils, R. COVID-19 Severity Correlates with Airway EpitheliumImmune Cell Interactions Identified by Single-Cell Analysis. Nat. Biotechnol. 2020, 38 (8), 970-979.

(112) Liao, M.; Liu, Y.; Yuan, J.; Wen, Y.; Xu, G.; Zhao, J.; Cheng, L.; Li, J.; Wang, X.; Wang, F.; Liu, L.; Amit, I.; Zhang, S.; Zhang, Z. SingleCell Landscape of Bronchoalveolar Immune Cells in Patients with COVID-19. Nat. Med. 2020, 26 (6), 842-844.

(113) Laing, A. G.; Lorenc, A.; del Molino del Barrio, I.; Das, A.; Fish, M.; Monin, L.; Muñoz-Ruiz, M.; McKenzie, D. R.; Hayday, T. S.; Francos-Quijorna, I.; Kamdar, S.; Joseph, M.; Davies, D.; Davis, R.; Jennings, A.; Zlatareva, I.; Vantourout, P.; Wu, Y.; Sofra, V.; Cano, F.; Greco, M.; Theodoridis, E.; Freedman, J.; Gee, S.; Chan, J. N. E.; Ryan, S.; Bugallo-Blanco, E.; Peterson, P.; Kisand, K.; Haljasmägi, L.; Chadli,
L.; Moingeon, P.; Martinez, L.; Merrick, B.; Bisnauthsing, K.; Brooks, K.; Ibrahim, M. A. A.; Mason, J.; Lopez Gomez, F.; Babalola, K.; AbdulJawad, S.; Cason, J.; Mant, C.; Seow, J.; Graham, C.; Doores, K. J.; Di Rosa, F.; Edgeworth, J.; Shankar-Hari, M.; Hayday, A. C. A Dynamic COVID-19 Immune Signature Includes Associations with Poor Prognosis. Nature Medicine 2020, 1-13.

(114) Jiang, H.; Li, Y.; Zhang, H.; Wang, W.; Yang, X.; Qi, H.; Li, H.; Men, D.; Zhou, J.; Tao, S. SARS-CoV-2 Proteome Microarray for Global Profiling of COVID-19 Specific IgG and IgM Responses. Nat. Commun. 2020, 11 (1), 1-11.

(115) Wang, H.; Hou, X.; Wu, X.; Liang, T.; Zhang, X.; Wang, D.; Teng, F.; Dai, J.; Duan, H.; Guo, S. SARS-CoV-2 Proteome Microarray for Mapping COVID-19 Antibody Interactions at Amino Acid Resolution. ACS Cent. Sci. 2020, 6, 2238.

(116) Nicora, C. D.; Sims, A. C.; Bloodsworth, K. J.; Kim, Y.-M.; Moore, R. J.; Kyle, J. E.; Nakayasu, E. S.; Metz, T. O. Metabolite, Protein, and Lipid Extraction (MPLEx): A Method That Simultaneously Inactivates Middle East Respiratory Syndrome Coronavirus and Allows Analysis of Multiple Host Cell Components Following Infection. Methods Mol. Biol. 2020, 2099, 173-194.

(117) Aging, Male Sex, Obesity, and Metabolic Inflammation Create the Perfect Storm for COVID-19. Diabetes https://diabetes. diabetesjournals.org/content/69/9/1857.abstract (accessed 2020-0919).

(118) Fang, X.; Li, S.; Yu, H.; Wang, P.; Zhang, Y.; Chen, Z.; Li, Y.; Cheng, L.; Li, W.; Jia, H.; Ma, X. Epidemiological, Comorbidity Factors with Severity and Prognosis of COVID-19: A Systematic Review and Meta-Analysis. Aging 2020, 12 (13), 12493-12503.

(119) Klein, S. L.; Dhakal, S.; Ursin, R. L.; Deshpande, S.; Sandberg, K.; Mauvais-Jarvis, F. Biological Sex Impacts COVID-19 Outcomes. PLoS Pathog. 2020, 16 (6), e1008570.

(120) Mahase, E. Covid-19: What Do We Know about "Long Covid"? BMJ 2020, 370, DOI: 10.1136/bmj.m2815.

(121) Cells I Free Full-Text I Mesenchymal Stromal Cell Secretome for Severe COVID-19 Infections: Premises for the Therapeutic Use. https://www.mdpi.com/2073-4409/9/4/924 (accessed 2020-11-26).

(122) Gujar, S.; Pol, J. G.; Kim, Y.; Kroemer, G. Repurposing CD8+ T Cell Immunity against SARS-CoV-2 for Cancer Immunotherapy: A Positive Aspect of the COVID-19 Pandemic? Oncoimmunology 2020, 9 (1), 1794424

(123) NCBI SARS-CoV-2 Resources. https://www.ncbi.nlm.nih. gov/sars-cov-2/ (accessed 2020-12-01).

(124) Kazuya, S.; Nao, N.; Matsuyama, S.; Kageyama, T. Ultra-Rapid Real-Time RT-PCR Method for Detecting Middle East Respiratory Syndrome Coronavirus Using a Mobile PCR Device, PCR1100. Jpn. J. Infect. Dis. 2020, 73 (3), 181-186.

(125) Lescure, F.-X.; Bouadma, L.; Nguyen, D.; Parisey, M.; Wicky, P.-H.; Behillil, S.; Gaymard, A.; Bouscambert-Duchamp, M.; Donati, F.; Hingrat, Q. L.; Enouf, V.; Houhou-Fidouh, N.; Valette, M.; Mailles, A.; Lucet, J.-C.; Mentre, F.; Duval, X.; Descamps, D.; Malvy, D.; Timsit, J.F.; Lina, B.; van-der Werf, S.; Yazdanpanah, Y. Clinical and Virological Data of the First Cases of COVID-19 in Europe: A Case Series. Lancet Infect. Dis. 2020, 20 (6), 697-706.

(126) Singh, P.; Chakraborty, R.; Marwal, R.; Radhakrishan, V. S.; Bhaskar, A. K.; Vashisht, H.; Dhar, M. S.; Pradhan, S.; Ranjan, G.; Imran, M.; Raj, A.; Sharma, U.; Singh, P.; Lall, H.; Dutta, M.; Garg, P.; Ray, A.; Dash, D.; Sivasubbu, S.; Gogia, H.; Madan, P.; Kabra, S.; Singh, S. K.; Agrawal, A.; Rakshit, P.; Kumar, P.; Sengupta, S. A Rapid and Sensitive Method to Detect SARS-CoV-2 Virus Using Targeted-Mass Spectrometry. J. Proteins Proteomics 2020, 11, 159-165.

(127) Silva, I. W. D.; Nayek, S.; Singh, V.; Reddy, J.; Granger, J. K.; Verbeck, G. F. Paper Spray Mass Spectrometry Utilizing Teslin ${ }^{\circledR}$ Substrate for Rapid Detection of Lipid Metabolite Changes during COVID-19 Infection. Analyst 2020, 145 (17), 5725-5732.

(128) CD, H. Coronavirus and PARP expression dysregulate the NAD Metabolome: a potentially actionable component of innate immunity. - Abstract - Europe PMC. https://europepmc.org/article/ med/32511303 (accessed 2020-12-01). 
(129) Jiang, H.-W.; Li, Y.; Zhang, H.-N.; Wang, W.; Yang, X.; Qi, H.; Li, H.; Men, D.; Zhou, J.; Tao, S.-C. SARS-CoV-2 Proteome Microarray for Global Profiling of COVID-19 Specific IgG and IgM Responses. Nat. Commun. 2020, 11 (1), 3581.

(130) Phipps, W. S.; SoRelle, J. A.; Li, Q.-Z.; Mahimainathan, L.; Araj, E.; Markantonis, J.; Lacelle, C.; Balani, J.; Parikh, H.; Solow, E. B.; Karp, D. R.; Sarode, R.; Muthukumar, A. SARS-CoV-2 Antibody Responses Do Not Predict COVID-19 Disease Severity. Am. J. Clin. Pathol. 2020, 154 (4), 459-465.

(131) Mauvais-Jarvis, F. Aging, Male Sex, Obesity, and Metabolic Inflammation Create the Perfect Storm for COVID-19. Diabetes 2020, 69 (9), 1857.

(132) Zaki, N.; Alashwal, H.; Ibrahim, S. Association of Hypertension, Diabetes, Stroke, Cancer, Kidney Disease, and High-Cholesterol with COVID-19 Disease Severity and Fatality: A Systematic Review. Diabetes \& Metabolic Syndrome: Clinical Research \& Reviews 2020, 14 (5), 1133-1142.

(133) Maras, J. S.; Sharma, S.; Bhat, A. R.; Aggarwal, R.; Gupta, E.; Sarin, S. K. Multi-Omics Integration Analysis of Respiratory Specimen Characterizes Baseline Molecular Determinants Associated with COVID-19 Diagnosis. medRxiv 2020, DOI: 10.1101/ 2020.07.06.20147082.

(134) Shu, Y.; McCauley, J. GISAID: Global Initiative on Sharing All Influenza Data - from Vision to Reality. Euro Surveill 2017, 22 (13), DOI: 10.2807/1560-7917.ES.2017.22.13.30494.

(135) Contou, D.; Claudinon, A.; Pajot, O.; Micaëlo, M.; Longuet Flandre, P.; Dubert, M.; Cally, R.; Logre, E.; Fraissé, M.; Mentec, H.; Plantefeve, G. Bacterial and Viral Co-Infections in Patients with Severe SARS-CoV-2 Pneumonia Admitted to a French ICU. Ann. Intensive Care 2020, 10 (1), 119.

(136) Lai, C.-C.; Wang, C.-Y.; Hsueh, P.-R. Co-Infections among Patients with COVID-19: The Need for Combination Therapy with Non-Anti-SARS-CoV-2 Agents? Journal of Microbiology, Immunology and Infection 2020, 53 (4), 505-512.

(137) Dennis, A. Multi-Organ Impairment in Low-Risk Individuals with Long COVID. Pre-print.

(138) Iacobucci, G. Long Covid: Damage to Multiple Organs Presents in Young Low Risk Patients. BMJ 2020, 371, DOI: 10.1136/ bmj.m4470.

(139) Struwe, W.; Emmott, E.; Bailey, M.; Sharon, M.; Sinz, A.; Corrales, F. J.; Thalassinos, K.; Braybrook, J.; Mills, C.; Barran, P. The COVID-19 MS Coalition-Accelerating Diagnostics, Prognostics, and Treatment. Lancet 2020, 395 (10239), 1761-1762.

(140) Rudnick, P. A.; Markey, S. P.; Roth, J.; Mirokhin, Y.; Yan, X.; Tchekhovskoi, D. V.; Edwards, N. J.; Thangudu, R. R.; Ketchum, K. A.; Kinsinger, C. R.; Mesri, M.; Rodriguez, H.; Stein, S. E. A Description of the Clinical Proteomic Tumor Analysis Consortium (CPTAC) Common Data Analysis Pipeline. J Proteome Res 2016, 15 (3), $1023-1032$. 